UNIVERSIDADE DE BRASÍLIA

FACULDADE DE EDUCAÇÃO FÍSICA

PROGRAMA DE PÓS-GRADUAÇÃO EM EDUCAÇÃO FÍSICA

\title{
PERFIL DO DESEMPENHO NEURONEUROMUSCULAR, MARCHA E EQUILÍBRIO EM INDIVÍDUOS ACOMETIDOS PELO ACIDENTE VASCULAR ENCEFÁLICO EM COMPARAÇÃO A CONTROLE PAREADOS
}

Rodrigo Rodrigues Gomes Costa

Brasília 


\title{
PERFIL DO DESEMPENHO NEURONEUROMUSCULAR, MARCHA E EQUILÍBRIO EM INDIVÍDUOS ACOMETIDOS PELO ACIDENTE VASCULAR ENCEFÁLICO EM COMPARAÇÃO A CONTROLE PAREADOS
}

\author{
Rodrigo Rodrigues Gomes Costa
}

\begin{abstract}
Dissertação apresentada à Faculdade de Educação Física da Universidade de Brasília, como requisito parcial para obtenção do grau de Mestre em Educação Física.
\end{abstract}

ORIENTADOR: Prof. Dr. RODRIGO LUIZ CARREGARO

Brasília 
Ficha catalográfica elaborada automaticamente, com os dados fornecidos pelo(a) autor(a)

RODRIGUES GOMES COSTA, RODRIGO

PERFIL DO DESEMPENHO NEURONEUROMUSCULAR, MARCHA E EQUILÍBRIO EM INDIVÍDUOS ACOMETIDOS PELO ACIDENTE VASCULAR ENCEFÁLICO EM COMPARAÇÃO A CONTROLE

PAREADOS / RODRIGO RODRIGUES GOMES COSTA; orientador RODRIGO LUIZ CARREGARO. -- Brasília, 2015.

$65 \mathrm{p}$.

Dissertação (Mestrado - Mestrado em Educação Física) -- Universidade de Brasília, 2015.

1. ACIDENTE VASCULAR ENCEFÁLICO. 2. FORÇA MUSCULAR. 3. MARCHA. 4. EQUILÍBRIO POSTURAL. 5. QUALIDADE DE VIDA. I. LUIZ CARREGARO, RODRIGO, orient. II. Título. 
Dedico ao Pai e ao meu pai. 


\section{AGRADECIMENTOS}

Já tentei escrever de várias formas,

E por mais que eu tentasse

Nada sai... apenas letras tortas.

Tem aquele padrão,

Deus, família, amigos e orientador,

Eu concordo com essa proposta.

Mas mudei a coloração.

Coloquei cores de uma escrita em versos,

Porque a ciência está muito cinza.

E agradecimentos, envolvem coisas sublimes,

De pessoas marcantes em pequenos gestos.

Pai, mãe, irmã e menina,

Além das gerações verticais e horizontais.

Amigos de Beagá e Brasília,

Me sustentaram na dura rotina.

Professores! Todos eles!

Orientador, outros de Londrina, Portugal...

Da pré escola à UNB.

Grandes humanos seres!

Todos colegas de reabilitação, mãezinha, filhinho e a origem Jupat.

Os aprendizados e incentivos, mesmo depois da prostração.

Obrigado ao pessoal de cima que me ensinou a subir sem passar por cima! 
"Sem trocar a alma pelas palmas, jamais... Mais que nunca sei onde pisei e porquê de tá aqui"

Emicida 


\section{SUMÁRIO}

INTRODUÇÃ

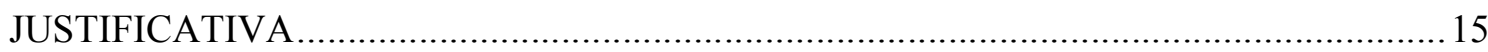

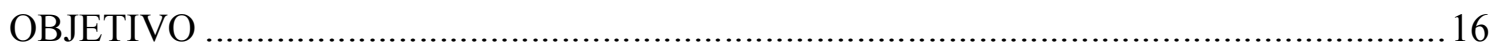

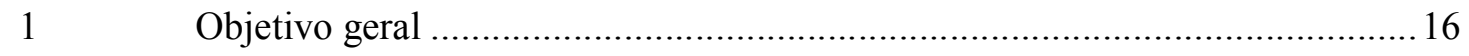

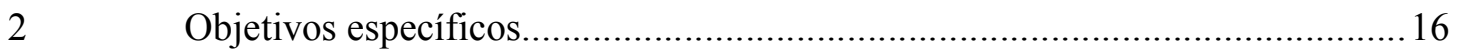

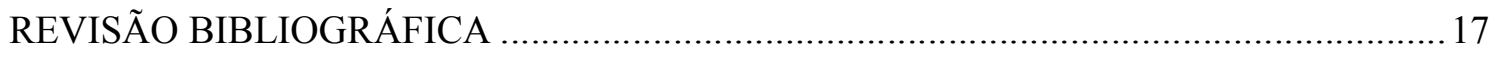

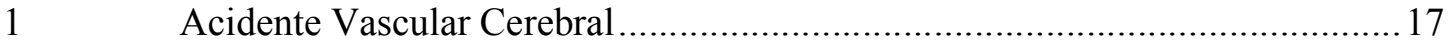

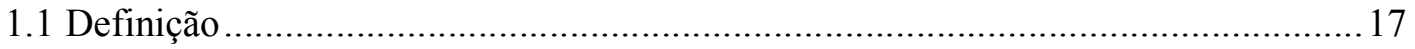

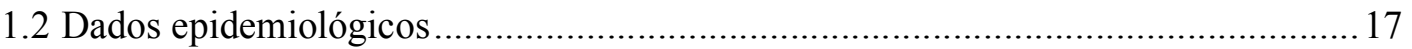

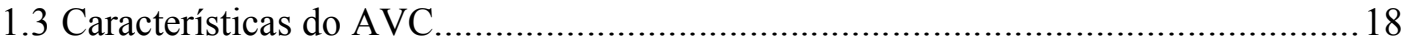

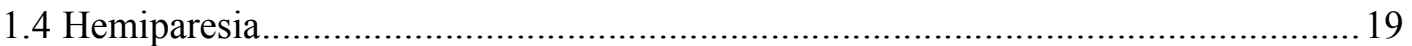

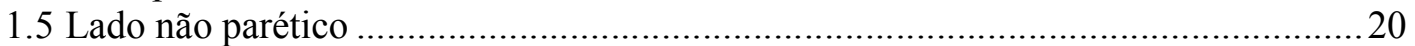

2 Modelos de Avaliação de Desempenho Neuromuscular..................................20

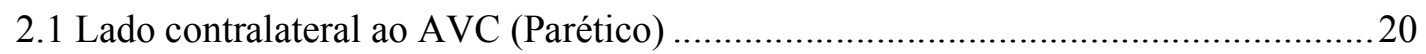

2.2. Lado ipsilateral ao AVC (Não Parético) ............................................................. 21

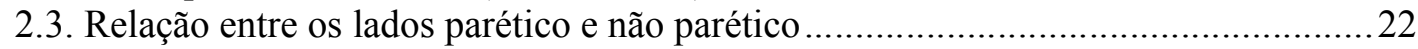

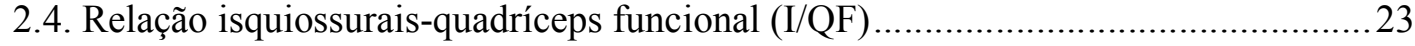

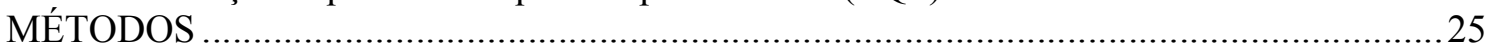

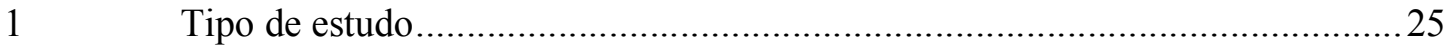

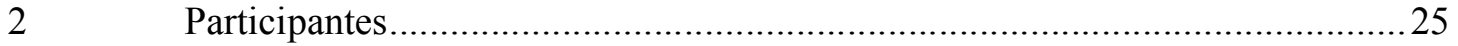

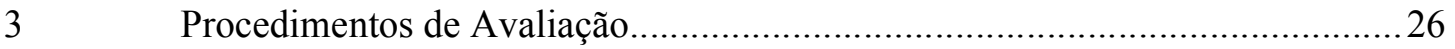

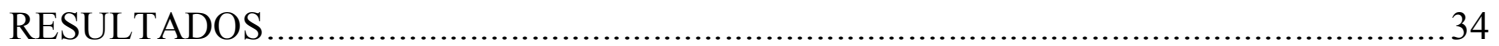

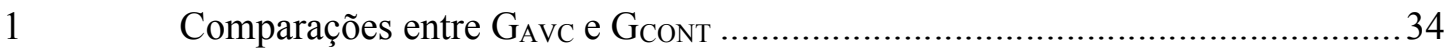

2 Correlação das variáveis de desempenho neuromuscular com a marcha, a qualidade de vida e o equilíbrio postural ............................ Erro! Indicador não definido.

3 Modelos de regressão linear múltipla................... Erro! Indicador não definido.

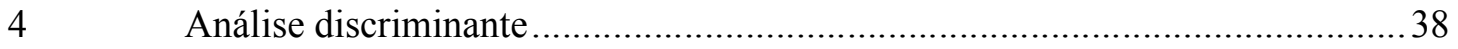

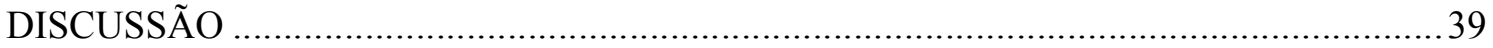

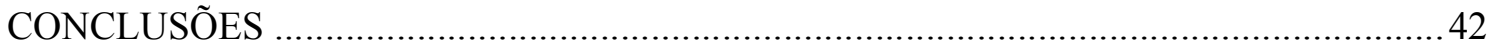

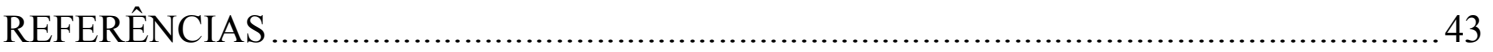

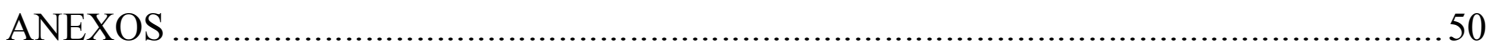




\section{LISTA DE TABELAS}

Páginas

TABELA 1 - Dados relativos à caracterização dos participantes do presente estudo............. 35

TABELA 2 - Comparação entre $\mathrm{G}_{\text {CONT }}$ e $\mathrm{G}_{\mathrm{AVC}}$, em relação às variáveis de desempenho neuromuscular da extensão concêntrica do joelho e I/QF no dinamômetro isocinético.......... 36

TABELA 3 - Comparação entre $\mathrm{G}_{\mathrm{CONT}}$ e $\mathrm{G}_{\mathrm{AVC}}$, em relação às variáveis de desempenho neuromuscular da flexão excêntrica do joelho no dinamômetro isocinético.......................... 36

TABELA 4 - Modelo de regressão linear múltipla com as variáveis de desempenho neuromuscular referentes ao pico de torque da extensão concêntricas de joelho com a marcha,

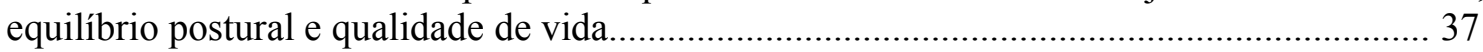

TABELA 5 - Modelo de regressão linear múltipla com as variáveis de desempenho neuromuscular referentes ao pico de torque da flexão excêntrica de joelho com a marcha, equilíbrio postural e qualidade de vida. 


\section{LISTA DE FIGURAS}

Páginas

FIGURA 1 - Diagrama com o fluxo dos procedimentos adotados no presente estudo........... 27

FIGURA 2 - Ilustração do processo de avaliação no Dinamômetro Isocinético...................... 30

FIGURA 3 - Protocolo do teste de força neuromuscular .................................................. 31 


\section{LISTA DE SIGLAS, ABREVIAÇÕES E SÍMBOLOS}

6MWT: Teste de caminhada de 6 minutos;

AVD: Atividades de vida diária;

AIVD: Atividades instrumentais de vida diária;

AVC: Acidente vascular cerebral;

DPT: Diferença entre o pico de torque entre os hemicorpos;

ES: Effect Size;

$\mathrm{G}_{\mathrm{AVC}}$ : Grupo de indivíduos acometidos pelo acidente vascular cerebral;

GCONT: Grupo controle;

ICC: Coeficiente de correlação intraclasse;

I/QF: Relação isquiossurais quadríceps funcional;

IMC: Índice de massa corporal;

MDC: Mínima mudança detectável;

MCID: Mínima diferença clinicamente importante;

OPS: Orpington Prognostic Scale;

OTP: Órtese tornozelo-pé;

PM: Potência Média;

PT: Pico de torque;

SARAH: Rede Sarah de Neurociência e Reabilitação;

SEM: medida de erro padrão;

SISrec: Percepção de recuperação da Stroke Impact Scale;

SIStotal: Pontuação total da Stroke Impact Scale;

SPT: Soma do pico de torque entre os hemicorpos;

SRD: Menor diferença real;

TCLE: Termo de Consentimento Livre e Esclarecido;

TPT: Tempo para atingir o pico de torque;

TT: Trabalho Total;

Vcon: Velocidade confortável de marcha;

Vmax: Velocidade máxima de marcha; 


\section{RESUMO}

Introdução: O acidente vascular cerebral (AVC) pode ocasionar a hemiparesia, caracterizada por alterações do tônus muscular, do controle motor e da força em um dos hemicorpos, também denominado membro parético. Sabe-se que também há comprometimento do lado não parético (ipsilateral a lesão encefálica). A força muscular de cada hemicorpo apresentam correlação a marcha e equilíbrio postural. A análise concomitante da força dos dois hemicorpos através da divisão ou subtração do membro não parético pelo membro parético também apresentam correlação com a marcha. Porém não existem estudos no momento que avaliaram a soma da força dos membros inferiores (SPT) e a relação isquiossurais quadríceps funcional (I/QF) em indivíduos acometidos pelo AVC. Objetivo: Comparar o desempenho neuromuscular, marcha, qualidade de vida e equilíbrio de indivíduos acometidos pelo AVC com um grupo controle sem lesão neurológica. Métodos: Dois grupos: Grupo experimental $\left(\mathrm{G}_{\mathrm{AVC}}\right)$ com 28 indivíduos acometidos pelo AVC com idade em mediana (25-75\%) de 52,5 (47-58) anos e tempo de lesão em anos (SD) de 43,4 (31,5) meses; Grupo Controle (GCONT) sem lesão encefálica com idade pareada. Avaliação da força muscular concêntrica dos extensores de joelho e excêntrica dos flexores do joelho no dinamômetro isocinético do lado parético e não parético do grupo experimental e dos dois hemicorpos do grupo controle. Avaliação da marcha com o teste de 10 metros e teste de caminhada de 6 minutos. A qualidade de vida foi avaliada pela Stroke Impact Scale. O equilíbrio postural foi avaliado pela escala de Berg. Resultados: 1) o tempo para atingir o pico de torque e a I/QF do lado não parético foram semelhantes ao comparar $G_{\text {CONT }}$ e o $G_{A V C}$. As outras todas variáveis apresentaram valores inferiores para o $\mathrm{G}_{\mathrm{AVC}} ; 2$ ) a SPT apresentou maior fator preditivo para a marcha; 3) o pico de torque, a potência média, o trabalho total do membro não parético e a potência média do membro parético foram as variáveis que melhor discriminaram o $\mathrm{G}_{\mathrm{AVC}}$ do

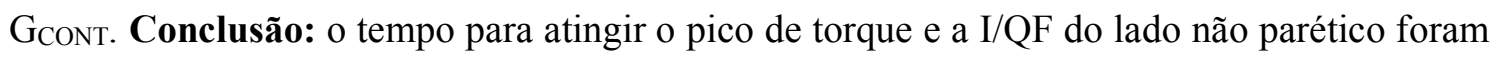
as únicas variáveis semelhantes ao comparar indivíduos com AVC e controle, além disso a SPT foi o maior fator preditivo para a marcha e o pico de torque, a potência média, o trabalho total (não parético) e a potência média (parético) foram as variáveis que melhor discriminaram os indivíduos com AVC.

Palavras-Chavc: acidente vascular cerebral; hemiparesia; força muscular; 


\begin{abstract}
Introduction: The stroke can lead to hemiparesis, characterized by changes in muscle tone, motor control and strength in one of hemibodies, also called paretic limb. It is known that there is also involvement of the non-paretic side (ipsilateral brain injury). Muscle strength of each hemisphere correlate gait and postural balance. Concomitant analysis of the strength of the two hemibodies by division or subtraction member of the non-paretic paretic member also correlate with the march. But there are no studies when evaluating the sum of the strength of the lower limbs (SPT) and the relationship hamstring quadriceps functional $(\mathrm{H} / \mathrm{QF})$ in individuals affected by stroke. Objective: To compare the neuromuscular and functional performance of chronic post-stroke with healthy subjects. Methods: twenty eight patients with median (25-75\%) of 52,5 (47-58) years, onset stroke with mean (SD) $43,4(31,5)$ months, and twenty eight age-matched controls. Concentric isokinetic torque of the extensor muscles of the knee and eccentric isokinetic torque of the flexor muscles of the knee of the affected and unaffected limb; in post-stroke patients and the two limbs in normal subjects, was assessed by isokinetic dynamometer. Walking performance was evaluated by using the 12-meter walking test and 6 minute walking test. Quality of life as measure by the Stroke Impact Scale and the Berg Scale to determine postural balance. Results: No difference in time to peak torque and functional hamstring to quadriceps ratio between patients and normal subjects was observed. The highest predictive value for walking performance are SPT. The peak torque, average power, total work of the affected limb and average power of the affected limb came out as the strongest's determinants of differentiation between chronic post-stroke with healthy subjects. Conclusion: the time to peak torque and the H/QF side not paretic were the only variables similar when comparing individuals with stroke and control, in addition to SPT was the most predictive factor for the walking performance and the peak torque, average power, total work (non-paretic) and the average power (paretic) were the variables that best discriminated individuals with stroke.
\end{abstract}

Key words: stroke; cerebrovascular accident; hemiparesis; muscle strength dynamometer; gait; quality of life; postural balance 


\section{INTRODUÇÃO}

O acidente vascular cerebral (AVC) é um déficit neurológico focal devido a infarto ou hemorragia de início rápido e duração de mais de 24 horas (1), sendo um dos principais problemas de saúde pública mundial (2). Nos Estados Unidos, o AVC ocupa a quarta posição entre todas as causas de morte (3) e no Brasil, apesar de apresentar um declínio em sua prevalência, representa uma das principais causas de mortalidade $(4,5)$.

O AVC pode ocasionar sequelas motoras, cognitivas e comportamentais. Dentre as sequelas mais frequentes, destaca-se a hemiparesia, caracterizada por alterações do tônus neuromuscular, do controle motor e da força em um dos hemicorpos (6), também denominado de lado parético.

Tradicionalmente, o membro parético é considerado como o principal parâmetro nas avaliações de desempenho neuromuscular e predição clínica em indivíduos com AVC (7-11). Em alguns estudos, a força do membro parético foi encontrada como fator preditor do desempenho de marcha (definida pelo Teste de Caminhada de 6 minutos) $(12,13)$, velocidade confortável de marcha $(10,11,14-16)$, cadência (passos por minuto) (17), independência para marcha (17), distância percorrida (17), subir e descer degraus $(15,18)$, mobilidade $(18,19)$, além da independência funcional (20) e equilíbrio postural dinâmico (19).

Em contrapartida, há evidências relativas ao comprometimento também do lado não parético (ipsilateral a lesão encefálica) (21-27), advindas de vários estudos que investigaram o desempenho neuromuscular desse hemicorpo (11-15, 17, 28-32). Estudos prévios demonstraram uma correlação da força do lado não-parético com a capacidade de locomoção (instrumento não especificado pelos autores) (33), velocidade confortável de marcha (14, 17, 29), cadência da marcha $(17)$, distância percorrida $(13,17)$ capacidade aeróbia $(11)$, controle de tronco (27) e capacidade de subir degraus $(15,34)$.

Tendo em vista as considerações relativas ao lado parético e não parético, há um corpo de conhecimento que indica o uso de avaliações do desempenho neuromuscular considerando os hemicorpos em concomitância. O primeiro estudo que propôs esse modelo foi no Japão, em $1985(35,36)$. Além de analisar os membros parético e não parético isoladamente, os autores propuseram a divisão do lado parético pelo lado não parético. Os achados demonstraram que os valores da relação diminuíam com o aumento da velocidade angular da contração, demonstrando que em movimentos rápidos, a força foi menor no lado parético.

Em 1991, Richard Bohannon (30) propôs uma fórmula caracterizada pela avaliação do déficit de força entre os hemicorpos ([força do membro não parético - força do parético] / força do não parético). Mais recentemente, em 2009, um estudo propôs a diferença da força 
do membro parético pelo não parético (37). Essas análises de relação entre os hemicorpos apresentaram implicações clínicas relevantes, tendo em vista seu fator preditivo para a velocidade confortável de marcha $(37,38)$, coordenação e habilidade de membros superiores (35).

Nota-se, assim, uma mudança nas perspectivas de avaliação do desempenho neuromuscular em indivíduos acometidos pelo AVC, baseando-se na relação entre os dois hemicorpos, por meio da diferença ou pela razão entre ambos. Uma das vantagens atribuídas a esse modelo é a possibilidade de compreender a severidade da assimetria (37). Entretanto, tais modelos que preconizam a relação entre os hemicorpos apresentam uma limitação ao interpretar os valores encontrados na avaliação, uma vez que não é possível analisar os dados absolutos de cada membro (37), ou até considerar semelhantes indivíduos que clinicamente são diferentes. Como exemplo, se um indivíduo apresenta um torque médio de extensão do joelho no lado parético de 30 N.m e no lado não parético 35 N.m, a diferença será de 5 N.m. Um outro indivíduo que apresenta um torque médio do lado parético de 100 N.m e do lado não parético de 105 N.m, também apresenta uma diferença de 5 N.m. Deste modo, a interpretação da diferença de força pode impor um viés, ao considerar os indivíduos como semelhantes, mesmo com valores absolutos de força distintos.

Considerando a importância de se interpretar a relação da força neuromuscular dos dois hemicorpos, mas sabendo das limitações do uso da diferença e da razão entre eles, este estudo propõe um novo modelo de análise do desempenho neuromuscular que ainda não foi apresentado na literatura, envolvendo o lado parético e o lado não parético: a soma da força de ambos os membros. Apesar desse novo modelo não permitir a análise do valor de cada membro, assim como na diferença e a razão, ele oferece um diferencial ao permitir a análise global do desempenho neuromuscular de indivíduos acometidos por AVC quanto ao seu potencial de força e desempenho.

No contexto da avaliação do desempenho neuromuscular, destaca-se a relação isquiossurais quadríceps funcional (I/QF), na qual se calcula a divisão da força máxima excêntrica dos isquiossurais pela força máxima concêntrica do músculo quadríceps (39). Esse índice permite verificar a presença de um desequilíbrio dinâmico na articulação do joelho, a qual tem sido considerada como consequência de várias lesões (40). Tratando-se dessas possibilidades de análise, a I/QF pode ser relevante na aplicação em indivíduos com AVC, uma vez que os mesmos apresentam alterações no recrutamento dos isquiossurais e quadríceps durante a marcha (41). Essas alterações podem ser caracterizadas por um recrutamento precoce e uma ativação desproporcionalmente elevada dos isquiossurais, além 
de uma subativação relativamente tardia do quadríceps (41), o que pode acarretar uma geração de força insuficiente do quadríceps e co-contração anormal dos isquiossurais durante a fase de balanço da marcha (42). 


\section{JUSTIFICATIVA}

Justifica-se o presente trabalho, na medida em que os resultados poderão auxiliar a prática clínica com novas possibilidades de avaliação neuromuscular em indivíduos acometidos pelo AVC. Além disso, os resultados poderão oferecer um embasamento adicional na definição ou não de intervenções com objetivos no ganho de força neuromuscular do membro parético, do membro não parético ou em ambos. 


\section{OBJETIVO}

\section{Objetivo geral}

Comparar o desempenho neuromuscular, marcha, qualidade de vida e equilíbrio de indivíduos acometidos pelo AVC com um grupo controle sem lesão neurológica.

\section{Objetivos específicos}

1) Comparar o desempenho neuromuscular do membro parético e do membro não parético com de indivíduos acometidos pelo AVC com indivíduos sem lesão neurológica.

2) Avaliar qual das diferentes avaliações neuromusculares apresentam maior fator preditivo da marcha, da qualidade de vida e do equilíbrio postural em indivíduos acometidos pelo AVC;

3) Analisar quais das avaliações de desempenho neuromuscular melhor discriminam indivíduos acometidos pelo AVC dos indivíduos sem lesão neurológica. 


\section{REVISÃO BIBLIOGRÁFICA}

\section{Acidente Vascular Cerebral}

\subsection{Definição}

O termo Acidente Vascular Cerebral (AVC) refere-se à tradução do termo Stroke. Essa terminologia foi utilizada pela primeira vez em 1689 por William Cole em seu clássico livro "Um Ensaio Físico-Médico Relativo às Frequências Tardias de Apoplexias" (A PhysicoMedical Essay Concerning the Late Frequencies of Apoplexies) para descrever lesões cerebrais não traumáticas agudas substituindo o termo apoplexia $(43,44)$. Ainda, o AVC é definido como um déficit neurológico atribuído a uma lesão focal aguda do sistema nervoso central por uma causa vascular (43).

No Brasil, além do termo Acidente Vascular Cerebral, outras duas denominações são utilizadas: Acidente Vascular Encefálico e Derrame. Esse último é utilizado principalmente pela população leiga, entretanto, não é adequada pois sugere um derramamento de sangue e nem sempre há um evento hemorrágico no AVC. O termo Acidente Vascular Encefálico (AVC) amplia o conceito, uma vez que o evento vascular pode ocorrer não somente no cérebro, como também em todo o encéfalo. No entanto, o termo AVC não acompanha a literatura internacional, na qual o cérebro é citado comumente como o conjunto de todas as estruturas do crânio. Além do termo AVC ser pouco conhecido internacionalmente, abre margem para conflito com outras doenças (45).

\subsection{Dados epidemiológicos}

O AVC é um dos principais problemas de saúde pública no mundo (2), sendo a quinta causa de mortalidade entre os homens e a terceira principal causa entre as mulheres (46). É a primeira causa de deficiências motoras em muitos países (47) e lidera as causas de disfunção física crônica (48). Dois terços de todas as mortes por AVC ocorrem em países de baixa e média renda, incluindo países da América Latina, no entanto, existem poucos estudos epidemiológicos com essa população nessas regiões (49).

Comparado a todos os países da América Latina, o Brasil apresenta a quarta maior taxa de mortalidade por AVC (4), sendo que, no país, o AVC é uma das principais causas de morte e incapacidade física $(4,50)$. No Brasil, houve uma redução de mortalidade desde o 
século XX até a primeira década do século XXI (51). Apesar dessa redução, o país mantém valores superiores comparados aos países mais desenvolvidos e à América do Sul $(49,51$, $52)$.

A causa desses números elevados ainda é especulativa, mas uma das hipóteses remete à alta prevalência do AVC no Brasil em relação a outras regiões (53). Apesar de estudos terem sido realizados em algumas regiões específicas do Brasil $(5,54)$, os dados ainda não são suficientes para fornecer uma prevalência de base populacional (53).

\subsection{Características do AVC}

O AVC pode ser classificado primariamente em dois tipos: isquêmico e hemorrágico. O primeiro tipo representa $87 \%$ de todos os casos e ocorre devido à obstrução de um vaso sanguíneo que fornece sangue ao encéfalo, e acarreta o desenvolvimento de depósitos de gordura que revestem a parede do vaso, sendo essa condição chamada de aterosclerose. Os depósitos de gordura podem causar dois tipos de obstrução: a trombose cerebral que se refere a um trombo (coágulo de sangue) que se desenvolve em parte do vaso obstruído; e a embolia cerebral na qual forma-se um coágulo em outro local no sistema circulatório. O tipo hemorrágico representa $13 \%$ dos casos de AVC e é caracterizado por um vaso enfraquecido que se rompe no encéfalo e gera o acúmulo de sangue, que comprime a área circundante. Dois tipos de vasos enfraquecidos podem romper: o aneurisma que é uma dilatação formada na área enfraquecida do vaso; e a má formação arteriovenosa que é um conjunto de vasos sanguíneos anormalmente formados (55).

O estágio agudo da doença é caracterizado por uma flacidez, arreflexia, hemiplegia, hemianestesia e alterações cognitivas resultantes da lesão cerebral de acordo com sua localização (56). A duração desse estágio pode terminar em 15 a 30 dias, quando o curso clínico é modificado e, em seguida, o indivíduo vai para a fase subaguda, que dura 1 a 3 meses e pode chegar a 6 meses $(55,57,58)$. Após 6 meses, aproximadamente a metade dos indivíduos acometidos pelo AVC apresenta déficit residual incluindo fraqueza ou disfunção cognitiva (59).

Além dessas alterações, outras deficiências significativas são observadas em indivíduos pós AVC incluindo fadiga generalizada, perda do controle motor voluntário, espasticidade e disfunção de sensibilidade (48, 60-69). 
$\mathrm{Na}$ maioria dos casos, o retorno da função ocorre espontaneamente em 1 a 3 meses após o AVC, atingindo um platô de seis meses a um ano após a lesão, embora alguns indivíduos apresentem recuperação substancial nas fases posteriores (70-72). Entretanto, mesmo após a fase de tratamento, menos de $40 \%$ atingem a recuperação motora completa (73).

\subsection{Hemiparesia}

A hemiparesia é definida como uma deficiência motora do lado corporal contralateral ao evento cerebrovascular (74). Estima-se que $65 \%$ dos indivíduos acometidos pelo AVC experimentaram uma disfunção motora hemiparética até 1 ano após a lesão encefálica (75) e na fase crônica, é um dos achados mais comuns, sendo o fator mais limitante do desempenho motor (76). A fraqueza é uma das características da hemiparesia, embora seja difícil diferenciá-la das deficiências de controle motor seletivo, sinergismo e hipertonia (74). No entanto, esses mecanismos de controle motor aberrante como anormalidades temporais e espaciais na ativação de músculos agonistas, ativação desproporcional dos músculos antagonistas e sinergistas e/ou deficiências das vias motoras descendentes (74) podem ser apresentados como fraqueza generalizada do lado parético (76).

Essa fraqueza apresenta correlação com a perda de autonomia (66), diminuição na velocidade de marcha (77), no desempenho de mudança da posição sentada para o ortostatismo (78-81), no desempenho de marcha, equilíbrio e atividade de vida diária $(82,83)$.

Uma das explicações fisiológicas para a hemiparesia envolve os aspectos neuromusculares. Porém, ao avaliar a área de secção transversa da musculatura dos membros inferiores por meio de tomografia computadorizada, não foram encontradas diferenças significantes quando o lado parético e o não parético foram comparados (84).

As explicações para essa característica da hemiparesia envolvem aspectos "não neuromusculares", uma vez que não há evidências de que as diferenças estruturais do músculo contribuem para a fraqueza hemiparética (74). Dentre os aspectos não neuromusculares, estão os mecanismos neurais, ou seja, para uma contração voluntária, a força neuromuscular é modulada por uma combinação de recrutamento de unidades motoras e mudanças na frequência e ativação dessas unidades, denominada taxa de codificação controlada pelo sistema nervoso central, em especial no córtex motor primário $(85,86)$. Porém, após o AVC, a lesão no tecido cerebral afeta as vias motoras corticoespinhal e supraespinhal, que ocasiona 
uma degeneração transsináptica no nível segmentar (74, 87). A consequente redução do tráfego neural no nível segmentar da coluna vertebral resulta em perda de neurônios (88) e em perturbações do mecanismo de controle da força primária (74). Além disso, observa-se uma relação da eletromiografia com o grau de força dos indivíduos com AVC (89-91), sugerindo que os indivíduos necessitam recrutar mais unidades motoras no membro parético para produzir a mesma magnitude de força/torque que o lado não parético (92).

\subsection{Lado não parético}

Há um crescente número de evidências indicando que a disfunção não ocorre somente no lado contralateral a lesão cerebral, mas também no lado ipsilateral - lado não parético (2125). Há mais de 30 anos atrás, o neuroanatomista Brodal (93) foi o primeiro a descrever uma deficiência motora à direita após uma hemiparesia à esquerda. Nesse estudo, o autor relata as alterações motoras, principalmente na escrita, presente nele mesmo. Colebatch \& Gandevia (94) encontraram que a lesão unilateral no córtex motor ou em suas projeções descendentes produz alguma fraqueza no lado não parético.

Existem algumas possíveis explicações para esse déficit, dentre os quais que o córtex motor primário pode exercer controle descendente bilateral sobre os movimentos distais; a lesão em um hemisfério pode alterar os sinais do corpo caloso e interromper o processamento neural no hemisfério oposto; a imobilidade após o $\mathrm{AVC}$; e a perda de peso devido às dificuldades nutricionais e de ingerir alimentos $(24,27,95)$.

\section{Modelos de Avaliação de Desempenho Neuromuscular}

\subsection{Lado contralateral ao AVC (Parético)}

Considerado como um dos achados mais comuns após o AVC, (76), o lado parético torna-se bastante presente nas avaliações de desempenho neuromuscular dessa população. $\mathrm{O}$ primeiro estudo encontrado na literatura que analisou a força do lado parético e correlacionou os dados com o desempenho funcional foi realizado em 1982, por Elisabeth Hamrin e colaboradores (33). Nesse estudo, a força do membro parético apresentou alta correlação (r entre 0,71 a 0,90) com a marcha (não foi especificado o teste utilizado). Entre 1985 e 1986, respectivamente, surgiram os estudos de Nakamura et al. (36) e Bohannon (8), os quais 
encontraram uma alta correlação entre a força do membro parético e a velocidade confortável de marcha e a cadência (passos por minuto). Em 1988, o estudo de Nakamura e colaboradores (31) demonstrou que a velocidade máxima de marcha foi determinada pela força dos extensores do joelho do membro parético.

A partir daí surgiu uma vasto corpo de conhecimento, que buscou compreender a correlação entre a força do membro parético com variáveis da marcha, como velocidade confortável $(9-12,14-18,28,30,34,38,96)$, velocidade máxima $(10,14,16,18,29,34,96$, 97), desempenho no Teste de 6 minutos $(12,13,18)$ (98), cadência (passos por minuto) (17), independência (8), distância percorrida (7), subir e descer degraus $(15,18,34)$, mobilidade $(18,19)$, além da independência funcional (20) e equilíbrio dinâmico (19).

\subsection{Lado ipsilateral ao AVC (Não Parético)}

Diante das evidências de que a disfunção ocorre não somente no lado parético, mas também no lado não parético $(21-25,27)$, surgiram estudos que verificaram o desempenho neuromuscular desse hemicorpo e suas repercussões em avaliações dos indivíduos acometidos pelo AVC. .Hamrin et al (33) realizaram o primeiro estudo, no qual correlacionaram positivamente a força do lado não parético com o desempenho da marcha, porém sem especificar qual variável da marcha foi analisada. Outros estudos correlacionaram a força do membro não parético com variáveis da marcha: cadência (passos por minuto), velocidade confortável, distância percorrida, independência (17) e velocidade máxima (29), equilíbrio dinâmico, mobilidade (19) controle de tronco (27) e capacidade de subir degraus $(15,34)$. Ainda, a força do lado não parético foi capaz de predizer a capacidade aeróbia de indivíduos com AVC (11), por meio de uma análise de regressão linear múltipla com a força do membro parético e a medida de independência funcional, além da força do não membro não parético. Entretanto, apenas essa última foi preditiva da capacidade aeróbia.

Nos estudos citados acima, todos envolveram a avaliação da força isométrica e/ou isocinética do membro não parético. No estudo de Bohannon \& Walsh (14), foi utilizada outra variável: o tempo para atingir o pico de torque. Os autores encontraram uma correlação com o tempo para atingir o pico de torque no lado não parético com a velocidade confortável $(\mathrm{r}=$ $0,74)$ e a velocidade máxima de marcha $(\mathrm{r}=-0,68)$. 


\subsection{Relação entre os lados parético e não parético}

Outro modelo de avaliação neuromuscular no contexto do AVC considera a relação da força neuromuscular dos hemicorpos. Nesse modelo, a força neuromuscular do lado parético ou não parético não são analisados de maneira isolada. O primeiro estudo que propôs esse modelo foi no Japão, em 1985 (36), no qual foi avaliado o torque da extensão de joelho do lado parético e do lado não parético, em condições isocinéticas em diferentes velocidades e em condição isométrica. Além de analisar os membros parético e não parético isoladamente, os autores propuseram uma razão entre o lado parético dividido pelo lado não parético. Os achados demonstraram que os valores da relação diminuíam com o aumento da velocidade angular da contração, demonstrando que em movimentos rápidos, a força foi menor no lado parético.

Bohannon (30) publicou o primeiro estudo que propôs uma fórmula que envolvia a força neuromuscular dos dois hemicorpos. Ainda, o estudo utilizou os resultados dessa fórmula na correlação com a distância percorrida e a velocidade confortável de marcha em indivíduos com AVC. A fórmula proposta envolve uma subtração da força do lado não parético com a força do lado parético, dividido pela força do lado não parético. Os achados demonstraram uma correlação de 0,64 com a velocidade confortável de marcha. Segundo Bohannon, esse valor foi superior ao encontrado na correlação do lado parético com a velocidade confortável em seu estudo prévio (30), o que permite concluir que esse modelo de análise possui alguma validade como medida de comprometimento funcional do AVC.

Outra proposta de análise realizou apenas a divisão da força do membro parético pelo não parético, denominado déficit de força, e correlacionou-o com testes de coordenação e habilidade, uma vez que esse estudo avaliou apenas os membros superiores (35). Os achados demonstraram que os maiores déficits de força entre os membros correlacionavam-se com os piores desempenhos nos testes. Nos modelos de regressão linear, o déficit de força explicou de 68 a 72\% da variação dos desempenhos de coordenação e habilidade de membros superiores. Os autores concluíram que, diante dessa correlação, o déficit de força apresentou um valor clínico de boa relação com o estado funcional dos membros superiores em indivíduos com AVC.

Um último e mais recente estudo encontrado na literatura avaliou a diferença entre a força do membro não parético com o parético $(37,99,100)$. Para essa análise, houve uma alta correlação com o desempenho e a velocidade confortável de marcha, sendo fator preditor para 
essa última variável. Diante desses resultados, a diferença de força entre os membros foi considerada uma abordagem com implicações clínicas importantes em intervenções com pessoas acometidas pelo AVC (66).

A vantagem desses modelos em comparação àqueles que analisam apenas um hemicorpo envolve a compreensão da severidade funcional da hemiparesia (37), utilizando o membro não parético como referência, mesmo considerando que esse lado também pode ter sido afetado (30).

\subsection{Relação isquiossurais-quadríceps funcional (I/QF)}

A relação da força máxima dos isquiossurais em relação à força máxima do quadríceps é um parâmetro comumente utilizado para descrever as propriedades da força neuromuscular na articulação do joelho (101). Ela é calculada pela divisão da força máxima de flexão do joelho pela força máxima extensão do joelho obtida em uma determinada velocidade e modo de contração dos músculos da coxa (isométrica, concêntrica ou excêntrica). Essa análise permite compreender os desequilíbrios neuromusculares do joelho e, apesar de não havcr consenso na literatura, considera-se um valor normativo para essa relação que seria de 0,6 (40).

Porém, diante do contexto da marcha envolver a ativação dos isquiossurais de forma excêntrica e o quadríceps de forma concêntrica, foi proposta outra relação entre as musculaturas (39), denominada relação isquiossurais quadríceps funcional (I/QF). A IQ/F baseia-se no cálculo da força máxima excêntrica dos isquiossurais divida pela força máxima concêntrica do quadríceps. Nessa relação, é possível indicar o quanto os isquiossurais são capazes de neutralizar o cisalhamento anterior da tíbia induzido pela contração do quadríceps. Os valores de 1 indicam uma capacidade dos músculos isquiossurais de proporcionar a estabilização articular dinâmica durante a extensão ativa do joelho. Os valores abaixo de 0,30 sugerem que os músculos isquiossurais têm uma capacidade reduzida de estabilização dinâmica articular do joelho durante os movimentos de flexão do joelho com simultânea contração excêntrica do quadríceps (39). O desequilíbrio neuromuscular na articulação do joelho tem sido associado com a etiologia de lesões musculoesqueléticas (40), e pode ser útil no âmbito do AVC ao oferecer informações aprofundadas sobre a dinâmica da articulação do joelho em uma população com diversas alterações da marcha e no equilíbrio. 
Vale ressaltar que os dados da relação I/QF referem-se a populações sadias e sem lesão neurológica, e até a presente data não foram encontrados estudos ou valores normativos para indivíduos com AVC. Sabe-se que, devido à lesão do Sistema Nervoso Central, o controle de inibição recíproca (após a ação do quadríceps, tida como agonista, reciprocamente inibe-se os músculos isquiossurais, antagonistas) é dificultado pela desinibição cortical (41, 102). A falta de inibição recíproca pode resultar em hipertonia do sistema flexor (flexores do quadril, isquiossurais e flexores plantares do tornozelo) ou co-espasticidade dos músculos extensores e flexores do quadril, que limitam a extensão de joelho e quadril durante a marcha (103). Tal desequilíbrio neuromuscular pode resultar em um recrutamento precoce e uma ativação desproporcionalmente elevada dos isquiossurais, além de uma ativação relativamente tardia do quadríceps (41), acarretando uma geração de força insuficiente do quadríceps e cocontração anormal dos isquiossurais durante a fase de balanço da marcha (42). 


\section{MÉTODOS}

\section{Tipo de estudo}

Trata-se de um estudo transversal controlado (analítico), realizado de acordo com as recomendações do Strobe Statement (104).

\section{Participantes}

A amostra foi não probabilística composta por indivíduos de ambos os sexos, divididos em dois grupos: indivíduos acometidos por pelo menos um AVC (G $\left.\mathrm{G}_{\mathrm{AVC}}\right)$ e indivíduos sadios e sem lesão encefálica (grupo controle; $\mathrm{G}_{\mathrm{CONT}}$ ). O G $\mathrm{CONT}$ foi utilizado como parâmetro de comparação da força do lado não parético do grupo experimental, verificando se esse apresenta alguma alteração como já apresentado em alguns estudos $(23,26)$. Os critérios de inclusão do $\mathrm{G}_{\mathrm{AVC}}$ foram: indivíduos acompanhados pela Rede Sarah de Neurociência e Reabilitação (SARAH), Brasília, DF, Brasil; que apresentaram valores superiores a um na Escala de Motricidade de Brunstrom (105). Os indivíduos eram excluídos caso apresentassem paresia ou plegia bilateral; alguma condição clínica que impossibilitasse a realização dos testes e avaliações; indivíduos que não conseguissem caminhar por pelo menos 10 metros sem assistência e aqueles que não compreendessem/expressassem pelo menos um comando verbal simples.

Para o $\mathrm{G}_{\mathrm{CONT}}$, os critérios de inclusão foram: residir em Brasília e não apresentar qualquer tipo de lesão encefálica. Os critérios de exclusão foram: apresentar alguma condição clínica que impossibilitasse a realização dos testes e avaliações; apresentar sequelas de lesões ortopédicas com repercussões na marcha. Os participantes foram incluídos com base no pareamento por sexo, idade e índice de massa corporal (IMC) com os indivíduos do $\mathrm{G}_{\mathrm{AVC}}$.

Foi realizado um cálculo amostral (software GPower versão 3.1.9), considerando-se um poder estatístico de $90 \%$ e um valor $\alpha$ de $5 \%(\alpha=0,05$; erro tipo I), de modo a detectar um efeito moderado $(f<0,5)$ na discriminação das variáveis de desempenho neuromuscular com a marcha, qualidade de vida e equilíbrio postural, sendo encontrado um valor de 60 indivíduos em cada grupo.

Após a aplicação dos critérios de inclusão e exclusão, os participantes foram convidados a participar por meio da assinatura de um Termo de Consentimento Livre e 
Esclarecido (TCLE). O estudo foi aprovado pelo Comitê de Ética em Pesquisa do SARAH, Brasília, DF, Brasil, (protocolo CAAE n. 36769514.0.0000.0022).

\section{Procedimentos de Avaliação}

Todos os participantes foram orientados a comparecer ao Laboratório de Treinamento de Força da Faculdade de Educação Física da Universidade de Brasília, para realização dos procedimentos de avaliação.

Inicialmente, cada participante e seu acompanhante receberam explicações sobre o estudo, instrumentos de avaliação e submetidos aos procedimentos de avaliação (Figura 1).

Em seguida foi realizada uma avaliação descritiva, caracterizada pela aplicação das escalas de Orpington Prognostic Scale (OPS) (Anexo I) que avalia a severidade do AVC, em que valores até 3 pontos representam "Bom prognóstico", de 3 a 5 pontos refere-se à um "Moderado prognóstico", e acima de 5 pontos: "Mal prognóstico" (106), Motricidade de Brunnstrom (Anexo II) para os membros inferiores que avalia a movimentação ativa nos quais variam de nenhum movimento voluntário ( 1 ponto) a movimentos combinados (6 pontos) (105), Escala modificada de Ashworth (7) (Anexo III) na qual avalia o tônus neuromuscular com uma variação do valor 0 (sem aumento de tônus neuromuscular) a 4 (rigidez de movimento), além da mensuração da massa corporal e estatura. Após cinco minutos de repouso, os participantes foram submetidos à avaliação da marcha e equilíbrio.

Após a aplicação das escalas e avaliação da marcha e equilíbrio, todos foram submetidos a um teste de força neuromuscular após um intervalo de descanso de 5 minutos, no Dinamômetro Isocinético.

Todas essas avaliações foram realizadas por avaliadores treinados em um período de sete meses no período matutino. 


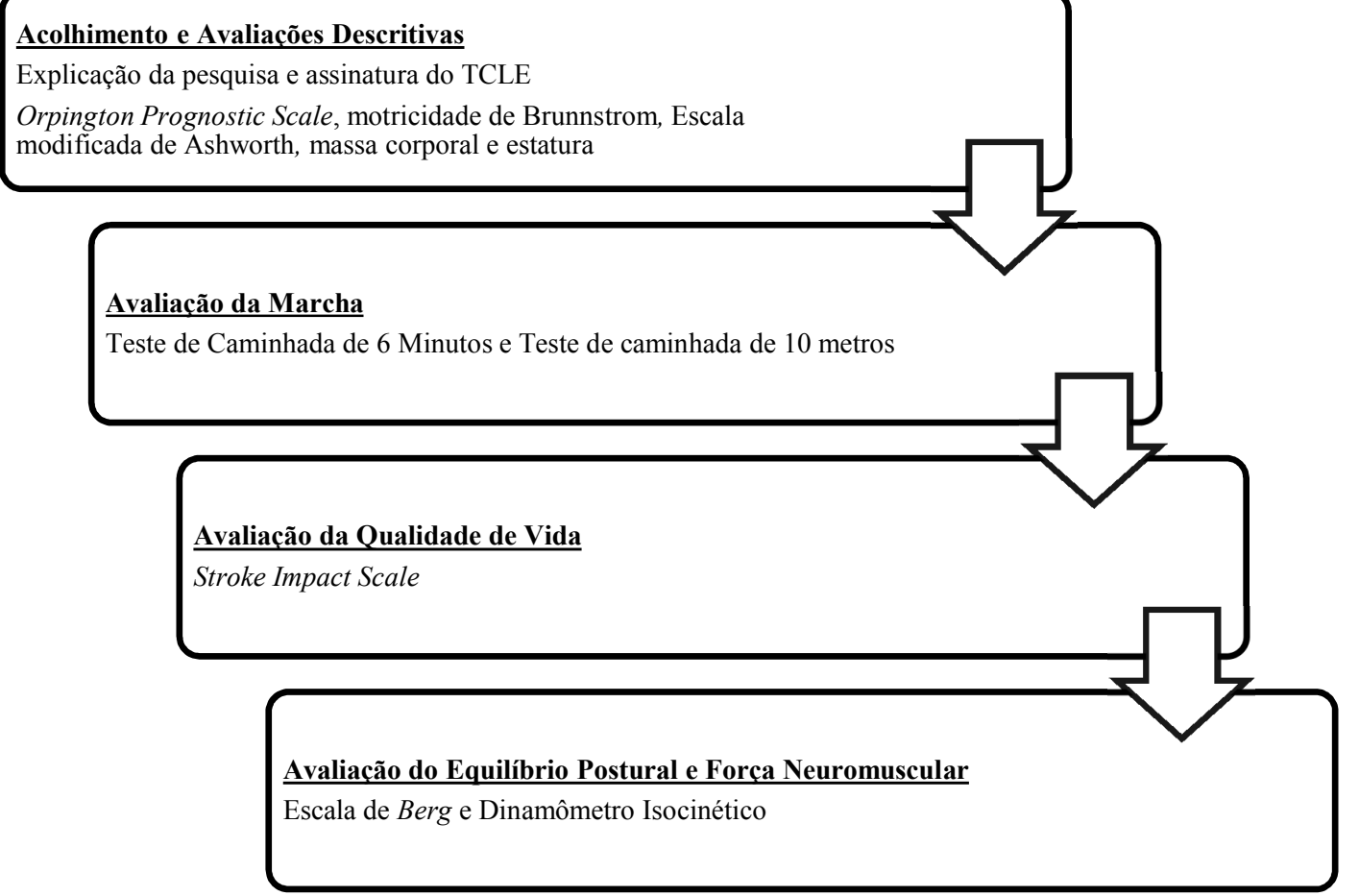

FIGURA 1 - Diagrama com o fluxo dos procedimentos adotados no presente estudo.

\subsection{Análise da Marcha}

Para avaliar a marcha, serão consideradas três variáveis: desempenho da marcha, velocidade confortável e máxima da marcha. Para a primeira variável, será utilizado o Teste de Caminhada de 6 minutos (6MWT) (107), usando uma distância de 30 metros. Os participantes serão instruídos a percorrer a maior distância possível durante os 6 minutos e serão autorizados, se necessário, parar e descansar durante esse período. Estarão liberados também a utilizar os seus dispositivos de auxílio locomoção e/ou órteses. Será oferecido um encorajamento padronizado (por exemplo, “você está indo muito bem, mantenha assim") em intervalos de 1 minuto. Se o participante pedir para descansar, o cronômetro não será interrompido e outras declarações serão oferecidas como: “já se passaram X minutos, fique o tempo que precisar”. Por fim, a distância total percorrida em metros será anotada. O 6MWT apresenta alta reprodutibilidade com coeficiente de correlação intraclasse (ICC) de 0,99 e a medida de erro padrão (SEM) de 4,8\% (108).

Foi utilizado o Teste de Caminhada de 10 metros, amplamente utilizado na avaliação de indivíduos com AVC (29-31, 36, 109). No teste, o participante é orientado a caminhar a distância de 14 metros, sendo que os 4 metros iniciais são descartados da análise, tendo em vista que é a distância necessária para que o voluntário atinja a velocidade desejada. No 
primeiro momento, para a avaliação da velocidade confortável (Vcon), os indivíduos foram orientados a caminhar com uma velocidade do seu cotidiano. Na velocidade máxima (Vmax), a orientação foi de caminhar com a maior velocidade possível desde que não corresse e sem risco de queda. Para o presente estudo, realizou-se três tentativas na velocidade confortável e outras três tentativas na velocidade máxima. A média de três tentativas, em cada velocidade, foi considerada para análise. Ambos os testes apresentam alta reprodutibilidade: Vcon, ICC de 0,94 e Vmax (ICC: 0,97) (108).

\subsection{Qualidade de Vida}

Para avaliar a qualidade de vida, foi utilizada a versão brasileira da Stroke Impact Scale 3.0 (110). Essa escala (SIStotal) inclui 59 itens e avalia oito domínios: força, função manual, atividades de vida diária/atividades instrumentais de vida diária (AVD/AIVD), mobilidade, comunicação, emoção/memória, pensamento e participação funcional. Cada item pode ser avaliado entre a pontuação 1 ("não consegue realizar") até a pontuação 5 ("nenhuma dificuldade"). Além disso, no último item, é possível obter a percepção de recuperação (SISrec) pontuada numa escala de 0 (nenhuma recuperação) a 100 (recuperação completa). Para a versão 3.0, só foi encontrado informações sobre a SEM, mínima mudança detectável (MDC) e a mínima diferença clinicamente importante (MCID) descritos a seguir de acordo com cada domínio, respectivamente, força: 8,7; 24,0; 9,2; AVD/AIVD: 6,3; 17,3; 5,9; mobilidade: 5,5; 15,1; 4,5; função manual: 9,4; 25,9; 17,8 (111).

\subsection{Avaliação do Equilíbrio Postural}

Para avaliar o equilíbrio postural, foi utilizada a escala de Berg (112). A escala é composta por 14 itens que avaliam quantitativamente o equilíbrio por meio da observação direta do desempenho dos participantes. Os itens são pontuados de 0 a 4, com uma pontuação de " 0 " representando uma incapacidade de completar a tarefa e uma pontuação de "4" representando a execução completa da tarefa.

A pontuação total é de 56, sendo que de 0 a 20 representa prejuízo de equilíbrio; 21 a 40 representa equilíbrio aceitável; e 41 a 56 representa um bom equilíbrio. A escala apresenta excelente reprodutibilidade em indivíduos acometidos pelo AVC com ICC de 0,95 e SEM de $1,68(113)$. 


\subsection{Dinamometria isocinética}

Foi utilizado um dinamômetro isocinético da marca Biodex System 3 (Biodex Medical Systems, Shirley, New York, USA) para avaliar o desempenho neuromuscular durante o exercício de extensão concêntrica do joelho e flexão excêntrica do joelho. No presente estudo, foram utilizadas as seguintes variáveis: pico de torque (PT) (N.m) normalizado pelo peso corporal (N.m/kg), trabalho total (TT) (em Joules), potência média (PM) (J/s) e o tempo para se atingir o pico de torque (TPT, em ms). Além dessas medidas instantâneas, foi calculado também a relação força neuromuscular excêntrica dos isquiossurais e a força neuromuscular concêntrica do quadríceps, também chamada de relação isquiossurais-quadríceps funcional (I/QF). Por fim, foram analisadas também a diferença do pico de torque (DPT) entre o lado parético e não parético $\left(\mathrm{G}_{\mathrm{AVC}}\right)$, não dominante e dominante $\left(\mathrm{G}_{\mathrm{CONT}}\right)$, além da soma do pico de torque entre os hemicorpos (SPT).

A calibração do dinamômetro foi realizada de acordo com as especificações do manual do fabricante. $\mathrm{O}$ sujeito foi posicionado na cadeira, com a possibilidade de um movimento livre e confortável de flexão e extensão do joelho. Neste processo, utilizou-se como parâmetro a extensão do joelho definida como $0^{\circ}$ e uma flexão a $90^{\circ}$, utilizando-se uma amplitude de movimento de flexo-extensão de $80^{\circ}$ (excursão desde os $90^{\circ}$ de flexão até $10^{\circ}$ ). $\mathrm{O}$ epicôndilo lateral do fêmur serviu como ponto de referência do eixo de rotação do joelho ao ser alinhado com o eixo de rotação do aparelho. A posição do quadril foi padronizada a $100^{\circ}$ de flexão (posicionamento da cadeira), para todos os participantes. A correção da gravidade foi obtida medindo-se o torque exercido pela almofada de resistência e a perna do participante (relaxada), na posição de extensão terminal. Os valores das variáveis isocinéticas foram automaticamente ajustados para a gravidade pelo programa Biodex Advantage 3. 


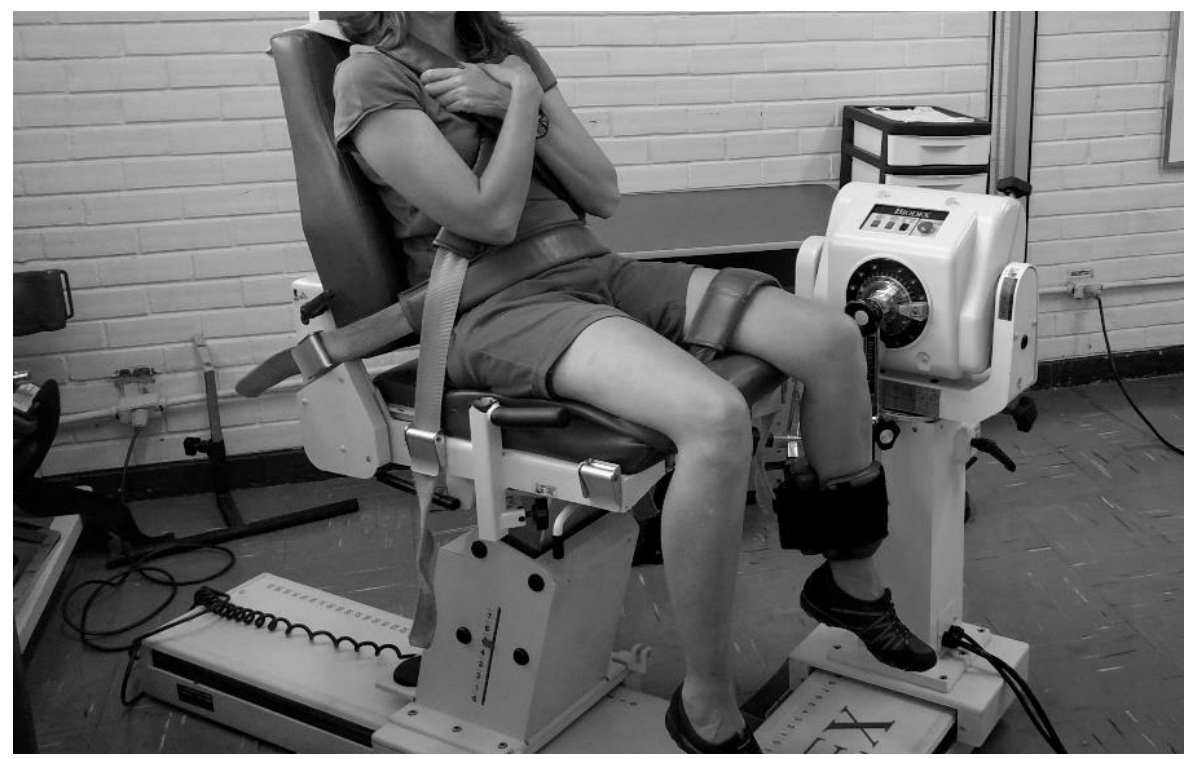

FIGURA 2 - Ilustração do processo de avaliação no Dinamômetro Isocinético.

Quanto à velocidade angular, foi demonstrado que pacientes após AVC não conseguem executar movimentos em altas velocidades com o membro parético, devido principalmente à atuação da musculatura antagonista espástica (114). Os estudos com extensão de joelho têm utilizado velocidades angulares entre 30 a $90 \%$ s $(29,33,96)$. Dessa forma, no presente estudo utilizou-se a velocidade angular de $60 \%$ s. A medida de força neuromuscular concêntrica de joelho a $60 \%$ em indivíduos acometidos pelo AVC tem apresentado alta reprodutibilidade, com coeficiente de correlação intraclasse (ICC) de 0,89 a 0,94; medida de erro padrão (SEM) de $7 \%$ a $12 \%$, e menor diferença real (SRD) de $26 \%$ a $48 \%$ (108).

Inicialmente, todos foram submetidos a uma familiarização caracterizada por duas séries de quatro repetições submáximas de extensão do joelho concêntricas, na velocidade de $60 \%$ s. Em seguida, foi verificado o coeficiente de variação entre as repetições de cada série submáxima. Caso o indivíduo não atingisse um coeficiente de variação inferior a $20,9 \%$ em nenhuma dessas séries, as mesmas eram repetidas. Se persistisse, mais duas séries eram realizadas. Mesmo se nessa terceira tentativa o valor do coeficiente de variação fosse superior a 20,9\%, o teste era realizado (Figura 3). 


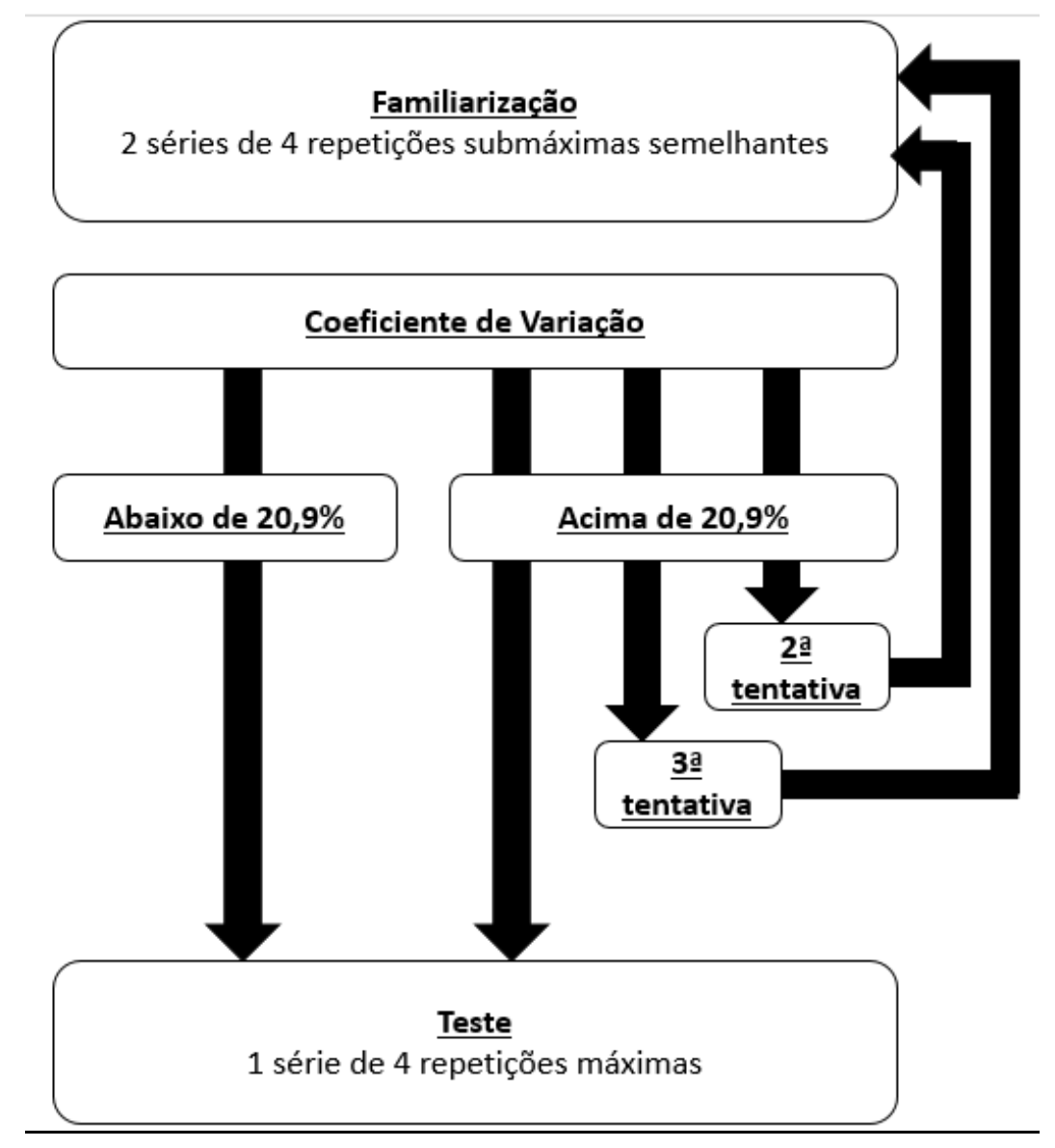

Figura 3 - Protocolo do teste de força neuromuscular.

O valor de 20,9\% foi assumido porque durante a execução do projeto piloto, os indivíduos acometidos pelo AVC permaneciam com valores até essa porcentagem. Além disso, não foram encontrados estudos analisando o coeficiente de variação em indivíduos com AVC na realização de testes de extensão e flexão de joelho no dinamômetro isocinético, e a população mais próxima que realizou esse tipo de teste foi a de idosos apresentando valores de 8 a $17 \%(115)$.

Após 2 minutos de intervalo, os voluntários executaram o protocolo de avaliação da força neuromuscular, composto por uma série de 4 repetições concêntricas máximas a $60 \%$ (96). Após concluir o teste máximo concêntrico, os voluntários tiveram 2 minutos de pausa, para realizar a mesma sequência, porém de um teste excêntrico de flexão de joelho (Fig. 3).

A ordem de início da avaliação dos membros inferiores foi membro não parético no $\mathrm{G}_{\mathrm{AVC}}$, e no $\mathrm{G}_{\mathrm{CONT}}$, o membro dominante. Dessa forma, as comparações intergrupos (GCONT versus $\left.\mathrm{G}_{\mathrm{AVC}}\right)$ ocorreram entre o lado dominante $\left(\mathrm{G}_{\mathrm{CONT}}\right)$ versus lado não parético $\left(\mathrm{G}_{\mathrm{AVC}}\right) \mathrm{e}$ 
lado não dominante $\left(\mathrm{G}_{\mathrm{CONT}}\right)$ versus parético $\left(\mathrm{G}_{\mathrm{AVC}}\right)$ como já descrito em estudos prévios $(23$, 26).

\subsection{Análise dos Dados}

Todas as análises foram realizadas no programa SPSS 17.0 (SPSS inc., Chicago, IL, EUA) e a significância adotada foi de $5 \%(p<0,05)$. Os pressupostos de normalidade dos dados foram verificados por meio do teste de Shapiro-Wilk. Os pressupostos sendo atendidos, os dados foram apresentados pela média e desvio-padrão. Caso contrário, quando os pressupostos não forem atendidos, os dados estão apresentados pela mediana e intervalo interquartil.

Para a comparação intergrupos $\left(\mathrm{G}_{\mathrm{CONT}}\right.$ versus $\left.\mathrm{G}_{\mathrm{AVC}}\right)$ referentes à extensão concêntrica de joelho, foi aplicado o teste $\mathrm{T}$ de Student para amostras independentes, com o intuito de verificar diferenças da DPT e SPT entre $\mathrm{G}_{\mathrm{CONT}}$ versus $\mathrm{G}_{\mathrm{AVC}}$, e das variáveis PT, PM e TPT do lado dominante $\left(\mathrm{G}_{\mathrm{CONT}}\right)$ comparado ao lado não parético $\left(\mathrm{G}_{\mathrm{AVC}}\right)$. O teste de Mann Whitney foi aplicado para verificar diferenças nas variáveis TT e I/QF na comparação do lado dominante $\left(\mathrm{G}_{\mathrm{CONT}}\right)$ versus lado não parético $\left(\mathrm{G}_{\mathrm{AVC}}\right)$ e nas variáveis PT, PM, TPT e I/QF do lado não dominante $\left(\mathrm{G}_{\mathrm{CONT}}\right)$ comparado ao lado parético $\left(\mathrm{G}_{\mathrm{AVC}}\right)$.

Para a comparação intergrupos $\left(\mathrm{G}_{\mathrm{CONT}}\right.$ versus $\left.\mathrm{G}_{\mathrm{AVC}}\right)$ referentes à flexão excêntrica de joelho, foi aplicado o teste $\mathrm{T}$ de Student para amostras independentes, com o intuito de verificar diferenças da DPT e SPT entre do $\mathrm{G}_{\mathrm{CONT}}$ versus $\mathrm{G}_{\mathrm{AVC}}$, TT do lado dominante ( $\left.\mathrm{G}_{\mathrm{CONT}}\right)$ comparado ao lado não parético $\left(\mathrm{G}_{\mathrm{AVC}}\right)$ e em relação ao PT do lado dominante ( $\left.\mathrm{G}_{\mathrm{CONT}}\right)$ comparado ao lado não parético $\left(\mathrm{G}_{\mathrm{AVC}}\right)$. O teste de Mann Whitney foi aplicado para verificar diferenças nas variáveis PT, PM e TPT na comparação do lado dominante (GCONT) versus lado não parético $\left(\mathrm{G}_{\mathrm{AVC}}\right)$ e nas variáveis TT, PM e TPT do lado não dominante (GCNT) comparado ao lado parético $\left(\mathrm{G}_{\mathrm{AVC}}\right)$.

O tamanho do efeito ( $d$ de Cohen) foi calculado pela fórmula:

$$
\mathrm{d}=\frac{M_{A V C}-M_{\text {Cont }}}{S D \text { Cont }}
$$

onde:

$\mathrm{M}_{\mathrm{AVC}}, \mathrm{M}_{\mathrm{Cont}}=$ Os valores médios da primeira e segunda análise

$\mathrm{SD}_{\text {Cont }}=$ Desvio padrão da primeira e segunda análise 
Esse cálculo foi aplicado nas comparações intergrupos ( $\mathrm{G}_{\mathrm{CONT}}$ versus $\left.\mathrm{G}_{\mathrm{AVC}}\right)$, nas variáveis PT, PM e TPT, para se determinar a magnitude da diferença. Para o tamanho do efeito dos dados não-paramétricos, as variáveis TT e I/QF na comparação do lado dominante $\left(\mathrm{G}_{\mathrm{CONT}}\right)$ versus lado não parético $\left(\mathrm{G}_{\mathrm{AVC}}\right)$ e nas variáveis PT, PM, TPT e I/QF do lado não dominante $\left(\mathrm{G}_{\mathrm{CONT}}\right)$ comparado ao lado parético $\left(\mathrm{G}_{\mathrm{AVC}}\right)$, os valores "z-score" do teste de comparações múltiplas de Wilcoxon foram convertidos para um tamanho do efeito estimado (r) por meio da fórmula:

$$
\mathrm{r}=\frac{Z}{\sqrt{N}}
$$

onde:

$$
\begin{aligned}
& \mathrm{Z}=\mathrm{Z} \text {-score } \\
& \mathrm{N}=\text { número de observações totais }
\end{aligned}
$$

Para o cálculo do tamanho do efeito das variáveis paramétricas, foram utilizados os valores propostos por Rhea (116) e baseados no cálculo do $d$ de Cohen, classificados como Trivial ( $d<0,35)$; Pequeno ( $d>0,35$ e $<0,80)$; Moderado $(d \geq 0,80$ e $<1,50)$ e Grande $(d \geq 1,5)$.

Em seguida, aplicou-se a Regressão Linear Múltipla com dois modelos: avaliação concêntrica de quadríceps e excêntrica de isquiotibiais, incorporando as variáveis independentes PT do membro parético, PT do membro não parético, DPT e SPT para verificar qual dessas variáveis apresenta maior fator preditivo nas variáveis dependentes 6MWT, Vcon, Vmax, Berg, SIStotal e SISrec. A validade do modelo foi avaliada através da análise estatística de colinearidade (fator de inflação da variância) e QQ-plot dos resíduos não padronizados, bem como a distância de Cook (influência da observação).

Para a análise discriminante, foram realizados dois modelos envolvendo em um deles as variáveis de extensão concêntrica de joelho e no outro a flexão excêntrica de joelho. A homogeneidade das matrizes de variância-covariância foi testada pelo teste Box's M. Em seguida, a análise discriminante foi aplicada pelo método Wilk's Lambda para identificar quais das variáveis PT, PM, TT, TPT, DPT, SPT e I/QF discriminariam significativamente os grupos $\mathrm{G}_{\mathrm{AVC}}$ e $\mathrm{G}_{\text {CONT. }}$ A correlação canônica foi usada para medir a associação entre os escores discriminantes e os grupos avaliados. Posteriormente, a análise classificatória foi aplicada para demonstrar a precisão de alocação dos participantes nas categorias e ainda a confirmação pela validação cruzada. 


\section{RESULTADOS}

\section{Comparações entre Gavc e Gcont}

A amostra foi formada por 28 indivíduos em cada grupo. Os dados demográficos e as características clínicas dos participantes estão apresentados na Tabela 1. Não foram encontradas diferenças significantes entre o $\mathrm{G}_{\mathrm{AVC}}$ e $\mathrm{G}_{\mathrm{CONT}}$ em relação à idade $(p=0,37)$, altura $(p=0,53)$, massa $(p=0,77)$ e IMC $(p=0,41)$.

Quando os grupos $\mathrm{G}_{\mathrm{AVC}}$ e $\mathrm{G}_{\mathrm{CONT}}$ foram comparados referentes às variáveis de desempenho neuromuscular da extensão concêntrica do joelho e I/QF, verificou-se que o PT, PM, TT, DPT e SPT foram significativamente maiores no $\mathrm{G}_{\mathrm{CONT}}(P<0,001)$. Verificou-se que tais diferenças ocorreram tanto no membro dominante do $\mathrm{G}_{\mathrm{CONT}}$ versus o não parético do $\mathrm{G}_{\mathrm{AVC}}$, quanto no membro não dominante do $\mathrm{G}_{\mathrm{CONT}}$ versus o parético do $\mathrm{G}_{\mathrm{AVC}}$ (Tabela 2). O $\mathrm{I} / \mathrm{QF}$ foi significativamente maior apenas ao comparar o membro não dominante do $\mathrm{G}_{\mathrm{CONT}}$ com o membro parético do $\mathrm{G}_{\mathrm{AVC}}(P<0,05)$.

O TPT não apresentou diferenças significantes entre o $\mathrm{G}_{\mathrm{CONT}}$ e o $\mathrm{G}_{\mathrm{AVC}}$, em nenhuma das comparações (Tabela 2).

Quando os grupos $\mathrm{G}_{\mathrm{AVC}}$ e $\mathrm{G}_{\mathrm{CONT}}$ foram comparados referentes às variáveis de desempenho neuromuscular da flexão excêntrica do joelho, verificou-se que no membro

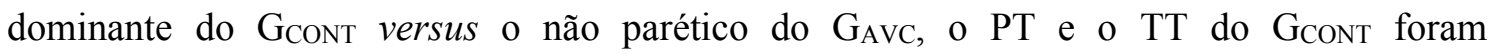
significativamente maiores $(P<0,05)$. Para o membro não dominante do $G_{\text {CONT versus o }}$ parético do $\mathrm{G}_{\mathrm{AVC}}$, o PT, TT e a PM, além da DPT e SPT, apresentaram valores significativamente maiores para o $\mathrm{G}_{\mathrm{CONT}}(P<0,001)$.

O TPT não apresentou diferenças significantes entre o $G_{C O N T}$ e o $G_{A V C}$, em nenhuma das comparações (Tabela 3). 
TABELA 1 - Dados relativos à caracterização dos participantes do presente estudo (GAVc: grupo acidente vascular cerebral; GCONT: grupo controle).

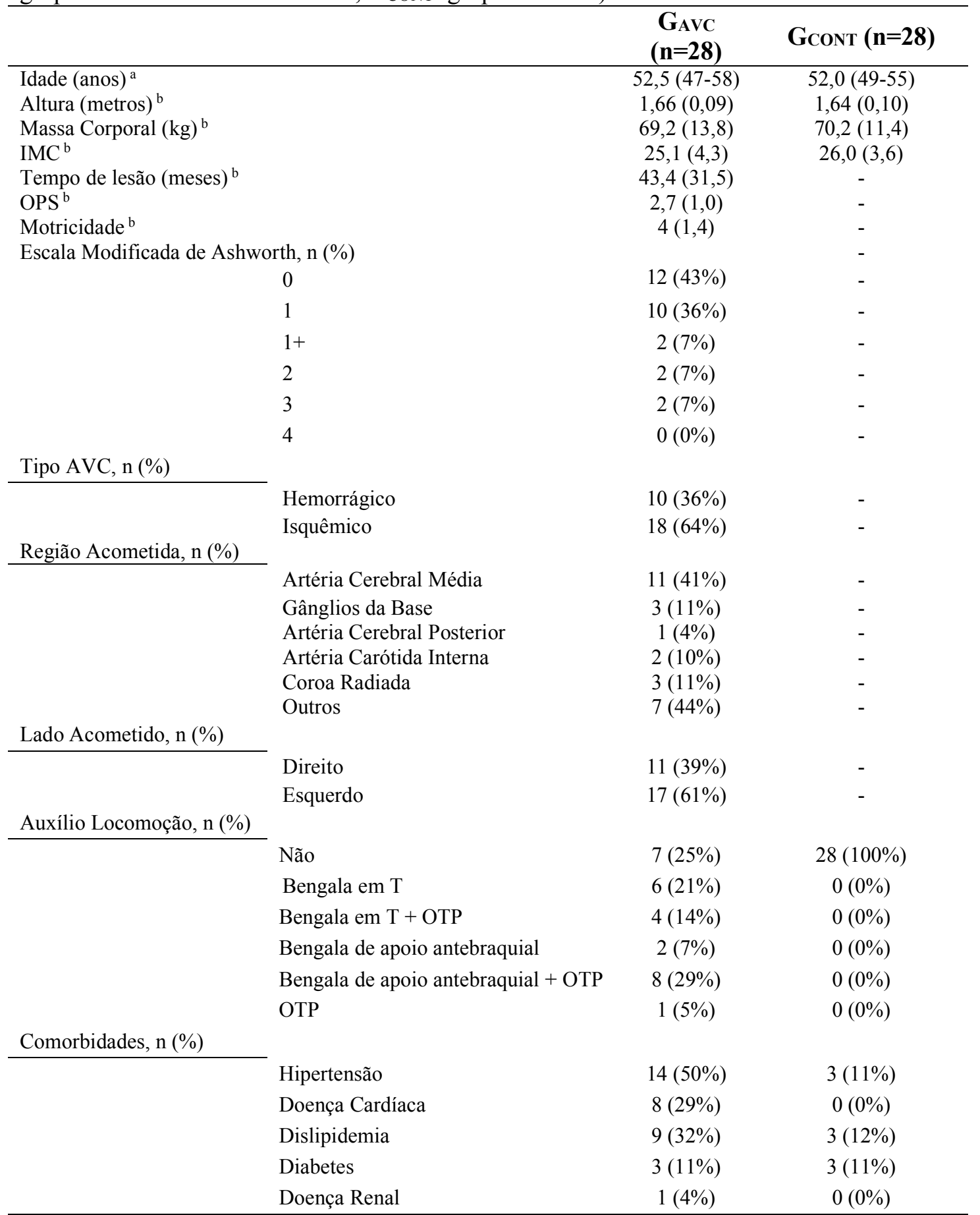

${ }^{\mathrm{a}}$ Resultados expressos em mediana (intervalo interquartil 25-75\%); ${ }^{\mathrm{b}}$ Resultados expressos em média (desvio padrão); AVC: Acidente Vascular Encefálico; IMC: índice de massa corporal; OPS: Orpington Prognostic Scale; OTP: órtese tornozelo-pé; 
TABELA 2 - Comparação entre $\mathrm{G}_{\mathrm{CONT}}$ e $\mathrm{G}_{\mathrm{AVC}}$, em relação às variáveis de desempenho neuromuscular da extensão concêntrica do joelho e I/QF no dinamômetro isocinético.

\begin{tabular}{|c|c|c|c|c|}
\hline & $\begin{array}{c}\text { GCoNT } \\
\text { Dominante }\end{array}$ & $\begin{array}{c}\text { GaVC } \\
\text { Não Parético }\end{array}$ & $\begin{array}{c}\text { ES } \\
\text { Gcont X GAVC }\end{array}$ & $P$-valor \\
\hline PT (N.m) ${ }^{b}$ & $123,3(110-162)$ & $107,3(94-145)$ & $-0,28$ & 0,032 \\
\hline $\mathrm{TT}(\mathrm{J})^{\mathrm{b}}$ & $384,6(332-519)$ & $325,6(251-397)$ & $-0,35$ & 0,008 \\
\hline $\mathrm{PM}(\mathrm{W})^{\mathrm{b}}$ & $69,5(62-89)$ & $55,5(56-79)$ & $-0,34$ & 0,009 \\
\hline $\mathrm{TPT}(\mathrm{ms})^{\mathrm{a}}$ & $580,6(132,4)$ & $543,6(234,5)$ & $-0,15$ & 0,474 \\
\hline \multirow[t]{2}{*}{$\mathrm{I} / \mathrm{QF}^{\mathrm{b}}$} & $0,79(0,64-0,88)$ & $0,77(0,69-0,84)$ & $-0,04$ & 0,737 \\
\hline & Não Dominante & Parético & & $P$-valor \\
\hline PT (N.m) ${ }^{b}$ & $123,4(100-149)$ & $51,2(23-79)$ & $-0,71$ & 0,001 \\
\hline TT $(J)^{b}$ & $369,3(311-473)$ & $123,0(59-252)$ & $-0,71$ & 0,001 \\
\hline $\mathrm{PM}(\mathrm{W})^{\mathrm{b}}$ & $68,8(58-89)$ & $23,2(12-47)$ & $-0,66$ & 0,001 \\
\hline $\mathrm{TPT}(\mathrm{ms})^{\mathrm{b}}$ & $560,0(470-635)$ & $500,0(333-638)$ & $-0,16$ & 0,219 \\
\hline $\mathrm{I} / \mathrm{QF}^{\mathrm{b}}$ & $0,77(0,64-0,89)$ & $0,97(0,69-1,41)$ & $-0,30$ & 0,023 \\
\hline $\mathrm{DPT}^{\mathrm{b}}$ & $7,2(0,08-22)$ & $53,75(31-79)$ & $-0,65$ & 0,001 \\
\hline $\mathrm{SPT}^{\mathrm{b}}$ & $240,4(209-315)$ & $157,4(128-214)$ & $-0,57$ & 0,001 \\
\hline
\end{tabular}

TABELA 3 - Comparação entre $G_{\text {CONT }}$ e $G_{A V C}$, em relação às variáveis de desempenho neuromuscular da flexão excêntrica do joelho no dinamômetro isocinético

\begin{tabular}{|c|c|c|c|c|}
\hline & $\begin{array}{c}\text { GCONT } \\
\text { Dominante }\end{array}$ & $\begin{array}{c}\text { GAVC } \\
\text { Não Parético } \\
\end{array}$ & $\begin{array}{c}\text { ES } \\
\text { Gcont X GAVC } \\
\end{array}$ & $P$-valor \\
\hline PT (N.m) ${ }^{b}$ & $100,2(90-113)$ & $85,9(72-105)$ & $-0,34$ & 0,011 \\
\hline $\mathrm{TT}(\mathrm{J})^{\mathrm{a}}$ & $311,3(105,74)$ & $242,8(103,90)$ & $-0,64$ & 0,018 \\
\hline $\mathrm{PM}(\mathrm{W})^{\mathrm{b}}$ & $43,1(39-60)$ & $37,9(30-48)$ & $-0,26$ & 0,045 \\
\hline \multirow[t]{2}{*}{ TPT $(\mathrm{ms})^{\mathrm{b}}$} & $750,0(360-1298)$ & $1225,0(243-1508)$ & $-0,12$ & 0,338 \\
\hline & Não Dominante & Parético & & $P$-valor \\
\hline PT (N.m) ${ }^{\mathrm{a}}$ & $98,2(24,3)$ & $59,3(26,2)$ & $-1,60$ & 0,001 \\
\hline TT $(J)^{b}$ & $300,2(260-396)$ & $128,1(75-214)$ & $-0,66$ & 0,001 \\
\hline $\mathrm{PM}(\mathrm{W})^{\mathrm{b}}$ & $42,7(37-54)$ & $21,5(11-34)$ & $-0,62$ & 0,001 \\
\hline $\mathrm{TPT}(\mathrm{ms})^{\mathrm{b}}$ & $1390,0(943-1525)$ & $1240,0(413-1530)$ & $-0,07$ & 0,594 \\
\hline $\mathrm{DPT}^{\mathrm{a}}$ & $6,8(21,8)$ & $28,9(18,9)$ & 1,01 & 0,001 \\
\hline $\mathrm{SPT}^{\mathrm{a}}$ & $203,1(43,5)$ & $147,5(48,8)$ & $-1,27$ & 0,001 \\
\hline
\end{tabular}

PT: Pico de torque; TT: Trabalho Total; PM: Potência Média; TPT: Tempo para atingir o pico de torque; ES: Effect Size; I/QF: Relação Isquiossurais quadríceps funcional; DPT: diferença do pico de torque entre os hemicorpos; SPT: soma do pico de torque dos hemicorpos; ${ }^{a}$ Resultados expressos em média (desvio padrão); ${ }^{b}$ Resultados expressos em mediana (intervalo interquartil 25-75\%). 


\section{Modelos de regressão linear múltipla}

No modelo de regressão linear múltipla com as variáveis de desempenho de desempenho neuromuscular referentes ao pico de torque da extensão concêntrica e flexão excêntrica do joelho (PT do membro parético, PT do membro não parético, DPT e SPT) com a marcha, equilíbrio postural e qualidade de vida, o PT do membro parético e não parético não atenderam os pressupostos e foram excluídos do modelo (Tabela 6 e 7).

A SPT apresentou maior fator preditivo em todas variáveis de marcha tanto na extensão concêntrica: 6MWT $\left(r^{2}\right.$ ajustado $\left.=0,27\right), \operatorname{Vmax}\left(r^{2}\right.$ ajustado $\left.=0,27\right)$ e Vcon $\left(r^{2}\right.$ ajustado $=0,21)$; quanto na flexão excêntrica de joelho: 6MWT $\left(\mathrm{r}^{2}\right.$ ajustado $\left.=0,25\right), \mathrm{Vmax}\left(\mathrm{r}^{2}\right.$ ajustado $=0,27)$ e Vcon $\left(r^{2}\right.$ ajustado $\left.=0,28\right)$. Para o equilíbrio postural e a qualidade de vida não houve nenhum fator preditivo estatisticamente significativo, em ambos modelos (concêntrico e excêntrico).

TABELA 6 - Modelo de regressão linear múltipla com as variáveis de desempenho neuromuscular referentes ao pico de torque da extensão concêntricas de joelho com a marcha, equilíbrio postural e qualidade de vida.

\begin{tabular}{cccccc}
\hline & \multicolumn{3}{c}{ DPT } & \multicolumn{2}{c}{ SPT } \\
\hline $\begin{array}{c}\text { Variáveis } \\
\text { Dependentes }\end{array}$ & $\mathrm{r}^{2}$ ajustado & Beta & $P$ & Beta & $P$ \\
\hline 6MWT & 0,27 & $-0,33$ & $0,01^{\dagger}$ & 0,34 & $0,011^{\dagger}$ \\
Vmax & 0,27 & $-0,32$ & $0,01^{\dagger}$ & 0,34 & $0,01^{\dagger}$ \\
Vcon & 0,21 & $-0,22$ & 0,09 & 0,37 & $0,01{ }^{\dagger}$ \\
Berg & 0,09 & $-0,28$ & $0,05^{\dagger}$ & 0,12 & 0,34 \\
SIStotal & $-0,03$ & 0,10 & 0,63 & $-0,17$ & 0,41 \\
SISrec & $-0,06$ & 0,14 & 0,50 & 0,09 & 0,67 \\
\hline Vmax: velocidade máxima de marcha; Vcon: velocidade confortável de marcha; 6MWT: teste de \\
caminhada de 6 minutos; SIStotal: pontuação total da Stroke Impact Scale; SISrec: percepção de \\
recuperação da Stroke Impact Scale; DPT: diferença do pico de torque entre os hemicorpos; SPT: \\
soma do pico de torque dos hemicorpos; Os valores de pico de torque dos membros não parético e \\
parético foram excluídos pelo modelo de regressão; ${ }^{\dagger} P \leq 0,05$.
\end{tabular}


TABELA 7 - Modelo de regressão linear múltipla com as variáveis de desempenho neuromuscular referentes ao pico de torque da flexão excêntrica de joelho com a marcha, equilíbrio postural e qualidade de vida.

\begin{tabular}{cccccc}
\hline & \multicolumn{2}{c}{ DPT } & \multicolumn{2}{c}{ SPT } \\
\hline $\begin{array}{c}\text { Variáveis } \\
\text { Dependentes }\end{array}$ & $\mathrm{r}^{2}$ ajustado & Beta & $P$ & Beta & $P$ \\
\hline 6MWT & 0,25 & $-0,28$ & $0,03{ }^{\dagger}$ & 0,39 & $0,01^{\dagger}$ \\
Vmax & 0,27 & $-0,28$ & $0,02^{\dagger}$ & 0,40 & $0,01^{\dagger}$ \\
Vcon & 0,28 & $-0,23$ & 0,06 & 0,45 & $0,01^{\dagger}$ \\
Berg & 0,12 & $-0,25$ & 0,06 & 0,23 & 0,08 \\
SIStotal & $-0,04$ & $-0,01$ & 0,98 & $-0,19$ & 0,35 \\
SISrec & $-0,07$ & $-0,10$ & 0,62 & 0,02 & 0,94 \\
\hline
\end{tabular}

Vmax: velocidade máxima de marcha; Vcon: velocidade confortável de marcha; 6MWT: teste de caminhada de 6 minutos; SIStotal: pontuação total da Stroke Impact Scale; SISrec: percepção de recuperação da Stroke Impact Scale; DPT: diferença do pico de torque entre os hemicorpos; SPT: soma do pico de torque dos hemicorpos; Os valores de pico de torque dos membros não parético e parético foram excluídos pelo modelo de regressão; ${ }^{\dagger} P \leq 0,05$

\section{Análise discriminante}

Em ambos os modelos de extensão concêntrica e flexão excêntrica do joelho, os valores de homogeneidade referentes às matrizes de variância-covariância testadas pelo teste Box's M foram de $P<0,001$.

No modelo concêntrico, as variáveis discriminantes para o $G_{A V C}$ foram o PT e a PM do membro não parético. No modelo excêntrico, as variáveis discriminantes para o $\mathrm{G}_{\mathrm{AVC}}$ foram a PM do membro parético e o TT do membro não parético. A porcentagem de indivíduos corretamente classificados pela análise classificatória foi de 89,3\% e 85,7\% e na validação cruzada foi de $83,9 \%$ e $78,6 \%$ referentes ao modelo concêntrico e excêntrico, respectivamente. A correlação canônica obteve valor de 0,76 para a extensão concêntrica e 0,75 para a flexão excêntrica de joelho. 


\section{DISCUSSÃO}

Os achados do presente trabalho demonstraram que o TPT em todas as análises e o $\mathrm{I} / \mathrm{QF}$ do lado não parético foram semelhantes ao comparar GCont e o G $\mathrm{G}_{\mathrm{AVC}}$. As outras variáveis apresentaram valores inferiores para o $G_{A V C}$. Ainda, a variável com maior valor preditivo para a marcha foi a SPT. Por fim, o estudo demonstrou que o PT, a PM (concêntricos) e o TT (excêntrico) do membro não parético e a PM (excêntrica) do membro parético foram as variáveis que melhor discriminaram o $\mathrm{G}_{\mathrm{AVC}}$ do $\mathrm{G}_{\mathrm{CONT}}$.

Em relação ao TPT, não foram encontradas diferenças significantes entre o GCNT $_{\text {Co }}$ o $\mathrm{G}_{\mathrm{AVC}}$, em todas as comparações. Nossos achados contradizem o único estudo encontrado até o momento que utilizou essa variável (117). Os autores verificaram que indivíduos acometidos pelo AVC apresentaram valores significativamente menores do TPT quando comparados a um grupo controle. Entretanto, não houve correlação entre o pico de torque e o TPT, e segundo os autores, tal achado sugere uma independência entre as duas variáveis. Essa independência pode justificar o comportamento diferenciado do pico de torque e do TPT no presente estudo, uma vez que a contração neuromuscular envolve não só o número de unidades motoras recrutadas, como também a frequência de disparos das mesmas (118). Outra possível explicação para a ausência de diferença do TPT entre os grupos pode ser o tempo de lesão. Os voluntários do estudo de Canning et al. apresentavam um quadro agudo (6 a 27 semanas), ao contrário do presente estudo no qual os participantes apresentavam um quadro crônico (mais de 2 anos). Deste modo, é possível supor que um paciente agudo tenha vivenciado um tempo menor de tratamento e, consequentemente, tenha sido exposto a pequenos efeitos das intervenções as quais foi submetido, em comparação com um indivíduo em fase crônica e a mais tempo sob tratamento.

Quanto às variáveis do membro parético PT, TT e PM apresentaram valores

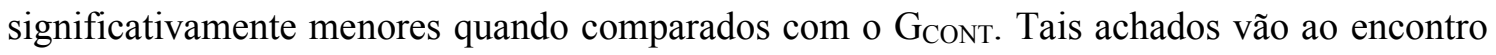
de estudos prévios que verificaram uma diminuição da força nesse hemicorpo $(33,82)$. Ao que parece, essa diminuição de força é explicada não só por uma diminuição das unidades motoras (88), mas também pela diminuição da taxa de disparo destas unidades (119). Existe uma lacuna na literatura sobre as avaliações de força neuromuscular que envolvam PM e TT em indivíduos acometidos pelo AVC. Em outras populações, há um consenso na literatura de que o PT está correlacionado com a PM e o TT, em especial quando existem fatores presentes como o envelhecimento, lesão ou processo de tratamento $(120,121)$. 
Assim como o membro parético, as variáveis do membro não parético apresentaram valores significativamente menores quando comparadas com o $\mathrm{G}_{\text {CONT. }}$ A diminuição de força neuromuscular do membro não parético (lado ipsilateral à lesão encefálica) já foi relatada em estudos prévios $(27,34)$. Tal achado é justificado pelo fato de que a lesão em um hemisfério pode alterar os sinais do corpo caloso e interromper o processamento neural no hemisfério oposto. Outro aspecto é a imobilidade física após o AVC e a perda de peso devido a dificuldades nutricionais e de ingerir alimentos $(24,27,95)$; além da atrofia neuromuscular ocorrida por essa imobilidade (118).

A SPT apresentou o maior fator preditivo para todas as variáveis da marcha. Estudos prévios demonstraram a correlação da força do membro parético $(11,12,15)$, do membro não parético (17), Suzuki, Nakamura et al. 1990), da diferença de força entre os membros (37). No presente estudo, foi possível analisar essas três abordagens, juntamente com a SPT, e verificar em um modelo de regressão com essas quatro variáveis que a SPT foi a variável com maior capacidade preditiva da marcha. Diferente do que ocorre com os modelos da razão ou diferença de força entre o membro parético e não parético, que avaliam o grau de comprometimento do AVC (30), a SPT apresenta a vantagem de compreender o potencial de força neuromuscular do indivíduo, sob um ponto de vista mais global. Além disso, os resultados da SPT envolveram tanto a contração concêntrica dos extensores do joelho como a contração excêntrica dos flexores de joelho. Diante dos resultados da correlação e dos modelos de regressão, a SPT apresentou uma importante aplicabilidade na avaliação do desempenho neuromuscular em indivíduos com AVC. Uma das limitações dessas conclusões refere-se ao valor do $\mathrm{r}^{2}$ ajustado nos modelos de regressão, os quais variaram entre 0,212 e 0,281, ou seja, as variáveis independentes do modelo proposto com a SPT, DPT e PT (parético e não parético) explicaram em apenas 21 a 28\% da marcha. Portanto, os resultados devem ser vistos com cautela.

Em relação aos dados da $\mathrm{I} / \mathrm{QF}$ do membro não parético, não foram encontradas diferenças significantes ao comparar o $\mathrm{G}_{\mathrm{AVC}}$ e $\mathrm{G}_{\text {CONT. }}$. Vale salientar que a I/QF é caracterizada por uma razão entre o PT da flexão excêntrica pelo PT da extensão concêntrica do joelho. Nesse sentido, os resultados da I/QF são contraditórios às comparações do PT entre os grupos, considerando que no presente estudo verificaram-se diferenças significantes entre ambos, para os valores brutos do PT. Ou seja, apesar do membro não parético apresentar uma fraqueza neuromuscular, justificada pelo córtex motor primário exercer controle descendente bilateral (27), ele mantém um equilíbrio neuromuscular semelhante a indivíduos sem lesão 
encefálica. Parece que essa perda de força neuromuscular ocorre de maneira proporcional, mas com a manutenção do equilíbrio neuromuscular da articulação do joelho.

As variáveis que melhor discriminaram os indivíduos com AVC daqueles sem lesão neurológica foram o PT, PM (excêntrico) e TT (concêntrico) do membro não parético. Demonstra-se, assim, a importância da inclusão da PM e TT nas avaliações de desempenho neuromuscular de indivíduos com AVC, adicionalmente ao PT que é tradicionalmente utilizado na prática clínica. O PT e a PM, quando analisados de forma conjunta, permitiram compreender a capacidade que o grupo neuromuscular possui de não apenas produzir força, mas também de gerar força de forma mais rápida e eficiente possível. Em relação à TT, diferente da PT, trata-se de uma variável que avalia de forma global o comportamento neuromuscular durante todo o arco de movimento (101), apresentando assim informações que não estão presentes nas outras variáveis e podem ser relevantes na avaliação de indivíduos acometidos pelo AVC. A PM (excêntrica) do membro parético também foi discriminante do $\mathrm{AVC}$, o que reforça a relevância da análise dos dois hemicorpos de indivíduos acometidos pelo AVC, nos quais as lesões podem ser unilaterais no córtex motor, mas geram repercussões em ambos os lados (94).

Outro aspecto refere-se às características da população avaliada no presente estudo, o qual envolveu indivíduos crônicos no acometimento do AVC (mais de dois anos de lesão), com bom prognóstico de acordo com a escala de severidade OPS e todos com passagem por um programa de reabilitação. Desse modo, torna-se relevante a realização de novos estudos avaliando outras fases clínicas da doença, com o intuito de ampliar a capacidade preditiva e verificar o padrão de resposta durante avaliações funcionais e de desempenho, como as aplicadas no presente estudo. 


\section{CONCLUSÕES}

O presente estudo demonstrou que, ao comparar indivíduos acometidos pelo AVC com sujeitos sem lesão encefálica, o tempo para atingir o pico de torque e a relação isquiossurais quadríceps funcional do membro parético foram semelhantes.

A soma do pico de torque dos membros inferiores é a variável com maior fator preditivo para a marcha. Ainda, a I/QF do membro parético apresentou maior fator preditivo da marcha e do equilíbrio postural.

Em relação à qualidade de vida, os achados demonstraram que o tempo para se atingir o pico de torque do membro não parético foi a variável com maior fator preditivo.

Por fim, o presente estudo demonstrou que as variáveis que melhor discriminaram os indivíduos acometidos pelo AVC daqueles sem lesão encefálica foram o pico de torque, a potência média e o trabalho total do membro não parético, e a potência média do membro parético.

As limitações do estudo envolvem a análise de apenas uma articulação dos membros inferiores, sendo relevante incluir outras musculaturas e articulações em estudos futuros. Além disso, o desenho do estudo não permite concluir relações de causa e efeito.

A implicação clínica com base nesses achados refere-se à relevância de incluir outras variáveis de desempenho neuromuscular no processo de avaliação de indivíduos com AVC, como a potência média, trabalho total, tempo para se atingir o pico de torque, além de um outro modelo de avaliação que se refere à soma da força dos hemicorpos, em especial, no acompanhamento da evolução da marcha. Podendo contribuir nas reflexões sobre as intervenções com treinamento de força, principalmente no que se refere a definição de priorizar somente o lado parético, o não parético ou em ambos. 


\section{REFERÊNCIAS}

1. Manji H, Kitchen N, Wills A, Connelly S, Dorward N, Mehta A. Oxford handbook of neurology: Oxford University Press; 2007.

2. Gordon NF, Gulanick M, Costa F, Fletcher G, Franklin BA, Roth EJ, et al. Physical activity and exercise recommendations for stroke survivors an American heart association scientific statement from the council on clinical cardiology, subcommittee on exercise, cardiac rehabilitation, and prevention; the council on cardiovascular nursing; the council on nutrition, physical activity, and metabolism; and the stroke council. Circulation. 2004;109(16):2031-41.

3. Compressed Mortality File 1999-2009. CDC Wonder Online Database, Compiled for Compressed Mortality File 1999-2009 Series 20, No. 20, 2012. Underlying Cause-of-Death 1999-2009. [Internet]. Acess November 2013. Available from: http://Wonder.Cdc.Gov/Mortsql.Html.

4. Lotufo PA. Stroke in Brazil: a neglected disease. Sao Paulo Med J. 2005;123(1):3-4.

5. Pereira ABCNd, Alvarenga H, Pereira Júnior RS, Barbosa MTS. Stroke prevalence among the elderly in Vassouras, Rio de Janeiro State, Brazil, according to data from the Family Health Program. Cad Saude Publica. 2009;25(9):1929-36.

6. Fisher CM. Ataxic hemiparesis: a pathologic study. Arch Neurol. 1978;35(3):126.

7. Bohannon RW, Smith MB. Interrater reliability of a modified Ashworth scale of muscle spasticity. Phys Ther. 1987;67(2):206-7.

8. Bohannon RW. Strength of lower limb related to gait velocity and cadence in stroke patients. Physiother Can. 1986;38(4):204-6.

9. Bohannon RW, Andrews AW. Correlation of knee extensor muscle torque and spasticity with gait speed in patients with stroke. Arch Phys Med Rehabil. 1990;71(5):330-3.

10. Nadeau S, Arsenault AB, Gravel D, Bourbonnais D. Analysis of the Clinical Factors Determining Natural and Maximal Gait Speeds in Adults With A Stroke1. Am J Phys Med Rehabil. 1999;78(2):123-30.

11. Wang W-T, Huang L-T, Chou Y-H, Wei T-S, Lin C-C. Nonparetic Knee Extensor Strength Is the Determinant of Exercise Capacity of Community-Dwelling Stroke Survivors. Sci World J. 2014;2014.

12. Patterson SL, Forrester LW, Rodgers MM, Ryan AS, Ivey FM, Sorkin JD, et al. Determinants of walking function after stroke: differences by deficit severity. Arch Phys Med Rehabil. 2007;88(1):115-9.

13. Pang MY, Eng JJ, Dawson AS. Relationship Between Ambulatory Capacity and Cardiorespiratory Fitness in Chronic StrokeInfluence of Stroke-Specific Impairments. CHEST Journal. 2005;127(2):495-501.

14. Bohannon R, Walsh S. Nature, reliability, and predictive value of muscle performance measures in patients with hemiparesis following stroke. Arch Phys Med Rehabil. 1992;73(8):721-5.

15. LeBrasseur NK, Sayers SP, Ouellette MM, Fielding RA. Muscle impairments and behavioral factors mediate functional limitations and disability following stroke. Phys Ther. 2006;86(10):1342-50.

16. Lindmark B, Hamrin E. Relation between Gait Speed, Knee Muscle Torque and Motor Scores in Post-Stroke Patients. Scand J Caring Sci. 1995;9(4):195-202.

17. Bohannon RW. Selected determinants of ambulatory capacity in patients with hemiplegia. Clin Rehabil. 1989;3(1):47-53.

18. Flansbjer U-B, Downham D, Lexell J. Knee muscle strength, gait performance, and perceived participation after stroke. Arch Phys Med Rehabil. 2006;87(7):974-80. 
19. Kligytė I, Lundy-Ekman L, Medeiros JM. Relationship between lower extremity muscle strength and dynamic balance in people post-stroke. Medicina. 2003;39(2):122-8.

20. Andrews AW, Bohannon RW. Distribution of muscle strength impairments following stroke. Clin Rehabil. 2000;14(1):79-87.

21. Jankowska E, Edgley SA. How can corticospinal tract neurons contribute to ipsilateral movements? A question with implications for recovery of motor functions. Neuroscientist. 2006;12(1):67-79.

22. Kim SH, Pohl PS, Luchies CW, Stylianou AP, Won Y. Ipsilateral deficits of targeted movements after stroke. Arch Phys Med Rehabil. 2003;84(5):719-24.

23. Marque P, Felez A, Puel M, Demonet J, Guiraud-Chaumeil B, Roques C, et al. Impairment and recovery of left motor function in patients with right hemiplegia. $\mathrm{J}$ Neurol Neurosurg Psychiatr. 1997;62(1):77-81.

24. Yarosh CA, Hoffman DS, Strick PL. Deficits in movements of the wrist ipsilateral to a stroke in hemiparetic subjects. J Neurophysiol. 2004;92(6):3276-85.

25. Yelnik A, Bonan I, Debray M, Lo E, Gelbert F, Bussel B. Changes in the execution of a complex manual task after ipsilateral ischemic cerebral hemispheric stroke. Arch Phys Med Rehabil. 1996;77(8):806-10.

26. Sunderland A. Recovery of ipsilateral dexterity after stroke. Stroke. 2000;31(2):430-3.

27. Harris M, Polkey M, Bath PM, Moxham J. Quadriceps muscle weakness following acute hemiplegic stroke. Clin Rehabil. 2001;15(3):274-81.

28. Bohannon RW. Knee extension force measurements are reliable and indicative of walking speed in stroke patients. Int J Rehabil Res. 1989;12(2):193.

29. Suzuki K, Nakamura R, Yamada Y, Handa T. Determinants of maximum walking speed in hemiparetic stroke patients. Tohoku J Exp Med. 1990;162(4):337-44.

30. Bohannon RW. Correlation of knee extension force and torque with gait speed in patients with stroke. Physiother Theory Pract. 1991;7(3):185-90.

31. Nakamura R, Watanabe S, Handa T, Morohashi I. The relationship between walking speed and muscle strength for knee extension in hemiparetic stroke patients: a follow-up study. Tohoku J Exp Med. 1988;154(2):111-3.

32. Noskin O, Krakauer JW, Lazar RM, Festa JR, Handy C, O'Brien KA, et al. Ipsilateral motor dysfunction from unilateral stroke: implications for the functional neuroanatomy of hemiparesis. J Neurol Neurosurg Psychiatr. 2008;79(4):401-6.

33. Hamrin E, Eklund G, Hillgren A-K, Borges O, Hall J, Hellström O. Muscle strength and balance in post-stroke patients. Ups J Med Sci. 1982;87(1):11-26.

34. Kim CM, Eng JJ. The relationship of lower-extremity muscle torque to locomotor performance in people with stroke. Phys Ther. 2003;83(1):49-57.

35. Boissy P, Bourbonnais D, Carlotti MM, Gravel D, Arsenault BA. Maximal grip force in chronic stroke subjects and its relationship to global upper extremity function. Clin Rehabil. 1999;13(4):354-62.

36. Nakamura R, Hosokawa T, Tsuji I. Relationship of muscle strength for knee extension to walking capacity in patients with spastic hemiparesis. Tohoku $\mathrm{J}$ Exp Med. 1985;145(3):335-40.

37. Kluding P, Gajewski B. Lower-extremity strength differences predict activity limitations in people with chronic stroke. Phys Ther. 2009;89(1):73-81.

38. Bohannon RW. Strength deficits also predict gait performance in patients with stroke. Percept Mot Skills. 1991;73(1):146-.

39. Aagaard P, Simonsen EB, Magnusson SP, Larsson B, Dyhre-Poulsen P. A new concept for isokinetic hamstring: quadriceps muscle strength ratio. Am J Sports Med. 1998;26(2):231-7. 
40. Coombs R, Garbutt G. Developments in the use of the hamstring/quadriceps ratio for the assessment of muscle balance. J Sports Sci Med. 2002;1(3):56.

41. Cutsuridis V. Does abnormal spinal reciprocal inhibition lead to co-contraction of antagonist motor units? A modeling study. Int J Neural Syst. 2007;17(04):319-27.

42. Thibaut A, Chatelle C, Ziegler E, Bruno M-A, Laureys S, Gosseries O. Spasticity after stroke: physiology, assessment and treatment. Brain Inj. 2013;27(10):1093-105.

43. Sacco RL, Kasner SE, Broderick JP, Caplan LR, Culebras A, Elkind MS, et al. An updated definition of stroke for the 21 st century a statement for healthcare professionals from the American Heart Association/American Stroke Association. Stroke. 2013;44(7):2064-89.

44. Cheung R. A Systematic Approach to the Definition of Stroke. Austin J Cerebrovasc Dis \& Stroke. 2014;1(5):1024.

45. Gagliardi RJ. Acidente Vascular Cerebral ou Acidente Vascular Encefálico? Qual a melhor nomenclatura. Rev Neurocienc. 2010;18(2):131-2.

46. Go AS, Mozaffarian D, Roger VL, Benjamin EJ, Berry JD, Borden WB, et al. Heart disease and stroke statistics-2013 update a report from the American Heart Association. Circulation. 2013;127(1):e6-e245.

47. Song R, Tong K-y, Hu X, Zhou W. Myoelectrically controlled wrist robot for stroke rehabilitation. J Neuroeng Rehabil. 2013;10(1):52.

48. Yang Y-R, Wang R-Y, Lin K-H, Chu M-Y, Chan R-C. Task-oriented progressive resistance strength training improves muscle strength and functional performance in individuals with stroke. Clin Rehabil. 2006;20(10):860-70.

49. Lavados PM, Hennis AJ, Fernandes JG, Medina MT, Legetic B, Hoppe A, et al. Stroke epidemiology, prevention, and management strategies at a regional level: Latin America and the Caribbean. The Lancet Neurology. 2007;6(4):362-72.

50. Mansur AdP, Favarato D, Souza MdFMd, Avakian SD, Aldrighi JM, César LAM, et al. Trends in death from circulatory diseases in Brazil between 1979 and 1996. Arquivos Brasileiros de Cardiologia. 2001;76(6):504-10.

51. Garritano CR, Luz PM, Pires MLE, Barbosa MTS, Batista KM. Análise da tendência da mortalidade por acidente vascular cerebral no Brasil no século XXI. Arq Bras Cardiol. 2012;98(6):519-27.

52. Koton S, Schneider AL, Rosamond WD, Shahar E, Sang Y, Gottesman RF, et al. Stroke incidence and mortality trends in US communities, 1987 to 2011. JAMA. 2014;312(3):259-68.

53. Kuster GW, Dutra LA, Brasil IP, Pacheco EP, Arruda MA, Volcov C, et al. Outcome Determinants of Stroke in a Brazilian Primary Stroke Center. Stroke research and treatment. 2014;2014.

54. Copstein L, Fernandes JG, Bastos GAN. Prevalence and risk factors for stroke in a population of Southern Brazil. Arquivos de neuro-psiquiatria. 2013;71(5):294-300.

55. Daffertshofer M, Mielke O, Pullwitt A, Felsenstein M, Hennerici M. Transient ischemic attacks are more than "ministrokes". Stroke. 2004;35(11):2453-8.

56. Modesto PC, Pinto FCG. Comparison of functional electrical stimulation associated with kinesiotherapy and kinesiotherapy alone in patients with hemiparesis during the subacute phase of ischemic cerebrovascular accident. Arq Neuropsiquiatr. 2013;71(4):244-8.

57. Johnston SC, Gress DR, Browner WS, Sidney S. Short-term prognosis after emergency department diagnosis of TIA. JAMA: the journal of the American Medical Association. 2000;284(22):2901-6.

58. Meschia JF, editor Subtyping in ischemic stroke genetic research. Seminars in Cerebrovascular Diseases and Stroke; 2002: Elsevier. 
59. Kelly-Hayes M, Beiser A, Kase CS, Scaramucci A, D'Agostino RB, Wolf PA. The influence of gender and age on disability following ischemic stroke: the Framingham study. J Stroke Cerebrovasc Dis. 2003;12(3):119-26.

60. Duncan P, Richards L, Wallace D, Stoker-Yates J, Pohl P, Luchies C, et al. A randomized, controlled pilot study of a home-based exercise program for individuals with mild and moderate stroke. Stroke. 1998;29(10):2055-60.

61. Engardt M, Knutsson E, Jonsson M, Sternhag M. Dynamic muscle strength training in stroke patients: effects on knee extension torque, electromyographic activity, and motor function. Arch Phys Med Rehabil. 1995;76(5):419-25.

62. Kim CM, Eng JJ, MacIntyre DL, Dawson AS. Effects of isokinetic strength training on walking in persons with stroke: a double-blind controlled pilot study. J Stroke Cerebrovasc Dis. 2001;10(6):265-73.

63. Moreland JD, Goldsmith CH, Huijbregts MP, Anderson RE, Prentice DM, Brunton $\mathrm{KB}$, et al. Progressive resistance strengthening exercises after stroke: a single-blind randomized controlled trial $<$ sup $>1,4</$ sup $>$. Arch Phys Med Rehabil. 2003;84(10):1433-40.

64. Ouellette MM, LeBrasseur NK, Bean JF, Phillips E, Stein J, Frontera WR, et al. Highintensity resistance training improves muscle strength, self-reported function, and disability in long-term stroke survivors. Stroke. 2004;35(6):1404-9.

65. Patten C, Dozono J, Schmidt SG, Jue ME, Lum PS. Combined Functional Task Practice and Dynamic High Intensity Resistance Training Promotes Recovery of Upperextremity Motor Function in Post-stroke Hemiparesis: A Case Study. J Neurol Phys Ther. 2006;30(3):99-115.

66. Patten C, Lexell J, Brown HE. Weakness and strength training in persons with poststroke hemiplegia: rationale, method, and efficacy. Journal of rehabilitation research and development. 2004;41(3):293-312.

67. Sharp SA, Brouwer BJ. Isokinetic strength training of the hemiparetic knee: effects on function and spasticity. Arch Phys Med Rehabil. 1997;78(11):1231-6.

68. Studenski S, Duncan PW, Perera S, Reker D, Lai SM, Richards L. Daily functioning and quality of life in a randomized controlled trial of therapeutic exercise for subacute stroke survivors. Stroke. 2005;36(8):1764-70.

69. Weiss A, Suzuki T, Bean J, Fielding RA. High intensity strength training improves strength and functional performance after stroke. Am J Phys Med Rehabil. 2000;79(4):36976.

70. Formisano R, Pantano P, Buzzi MG, Vinicola V, Penta F, Barbanti P, et al. Late motor recovery is influenced by muscle tone changes after stroke. Arch Phys Med Rehabil. 2005;86(2):308-11.

71. Hendricks HT, van Limbeek J, Geurts AC, Zwarts MJ. Motor recovery after stroke: a systematic review of the literature. Arch Phys Med Rehabil. 2002;83(11):1629-37.

72. Schaechter JD. Motor rehabilitation and brain plasticity after hemiparetic stroke. Prog Neurobiol. 2004;73(1):61-72.

73. Sung W-H, Wang C-P, Chou C-L, Chen Y-C, Chang Y-C, Tsai P-Y. Efficacy of Coupling Inhibitory and Facilitatory Repetitive Transcranial Magnetic Stimulation to Enhance Motor Recovery in Hemiplegic Stroke Patients. Stroke. 2013;44(5):1375-82.

74. Pak S, Patten C. Strengthening to promote functional recovery poststroke: an evidence-based review. Top Stroke Rehabil. 2008;15(3):177-99.

75. Cauraugh JH, Kim SB. Chronic stroke motor recovery: duration of active neuromuscular stimulation. J Neurol Sci. 2003;215(1):13-9.

76. Bourbonnais D, Bilodeau S, Lepage Y, Beaudoin N, Gravel D, Forget R. Effect of force-feedback treatments in patients with chronic motor deficits after a stroke. Am J Phys Med Rehabil. 2002;81(12):890-7. 
77. Bohannon RW. Standing balance, lower extremity muscle strength, and walking performance of patients referred for physical therapy. Percept Mot Skills. 1995;80(2):379-85.

78. Barzi Y, Zehr EP. Rhythmic arm cycling suppresses hyperactive soleus H-reflex amplitude after stroke. Clin Neurophysiol. 2008;119(6):1443-52.

79. Morris SL, Dodd KJ, Morris ME. Outcomes of progressive resistance strength training following stroke: a systematic review. Clin Rehabil. 2004;18(1):27-39.

80. Zehr EP. Evidence-based risk assessment and recommendations for physical activity clearance: stroke and spinal cord injury 11 This paper is one of a selection of papers published in this Special Issue, entitled Evidence-based risk assessment and recommendations for physical activity clearance, and has undergone the Journal's usual peer review process. Appl Physiol Nutr Metab. 2011;36(S1):S214-S31.

81. Zehr EP, Loadman PM. Persistence of locomotor-related interlimb reflex networks during walking after stroke. Clin Neurophysiol. 2012;123(4):796-807.

82. Bohannon RW. Muscle strength and muscle training after stroke. J Rehabil Med. 2007;39(1):14-20.

83. Teixeira-Salmela LF, Olney SJ, Nadeau S, Brouwer B. Muscle strengthening and physical conditioning to reduce impairment and disability in chronic stroke survivors. Arch Phys Med Rehabil. 1999;80(10):1211-8.

84. Sunnerhagen KS, Svantesson U, Lönn L, Krotkiewski M, Grimby G. Upper motor neuron lesions: their effect on muscle performance and appearance in stroke patients with minor motor impairment. Arch Phys Med Rehabil. 1999;80(2):155-61.

85. Kukulka CG, Clamann HP. Comparison of the recruitment and discharge properties of motor units in human brachial biceps and adductor pollicis during isometric contractions. Brain Res. 1981;219(1):45-55.

86. Moritani T, Muro M, Kijima A. Electromechanical changes during electrically induced and maximal voluntary contractions: electrophysiologic responses of different muscle fiber types during stimulated contractions. Exp Neurol. 1985;88(3):471-83.

87. Kamper DG, Fischer HC, Cruz EG, Rymer WZ. Weakness is the primary contributor to finger impairment in chronic stroke. Arch Phys Med Rehabil. 2006;87(9):1262-9.

88. McComas A, Sica R, Upton A, Aguilera N. Functional changes in motoneurones of hemiparetic patients. J Neurol Neurosurg Psychiatr. 1973;36(2):183-93.

89. Gemperline JJ, Allen S, Walk D, Rymer WZ. Characteristics of motor unit discharge in subjects with hemiparesis. Muscle Nerve. 1995;18(10):1101-14.

90. Tang A, Rymer W. Abnormal force--EMG relations in paretic limbs of hemiparetic human subjects. J Neurol Neurosurg Psychiatr. 1981;44(8):690-8.

91. Zhou P, Suresh NL, Rymer WZ. Model based sensitivity analysis of EMG-force relation with respect to motor unit properties: applications to muscle paresis in stroke. Ann Biomed Eng. 2007;35(9):1521-31.

92. Chang SH, Zhou P, Rymer WZ, Li S. Spasticity, weakness, force variability, and sustained spontaneous motor unit discharges of resting spastic-paretic biceps brachii muscles in chronic stroke. Muscle Nerve. 2013.

93. Brodal A. Self-observations and neuro-anatomical considerations after a stroke. Brain. 1973;96(4):675-94.

94. Colebatch J, Gandevia S. The distribution of muscular weakness in upper motor neuron lesions affecting the arm. Brain. 1989;112(3):749-63.

95. English C, McLennan H, Thoirs K, Coates A, Bernhardt J. Reviews: Loss of skeletal muscle mass after stroke: a systematic review. Int J Stroke. 2010;5(5):395-402.

96. Hsu A-L, Tang P-F, Jan M-H. Test-retest reliability of isokinetic muscle strength of the lower extremities in patients with stroke. Arch Phys Med Rehabil. 2002;83(8):1130-7. 
97. Suzuki K, Imada G, Iwaya T, Handa T, Kurogo H. Determinants and predictors of the maximum walking speed during computer-assisted gait training in hemiparetic stroke patients. Arch Phys Med Rehabil. 1999;80(2):179-82.

98. Pradon D, Roche N, Enette L, Zory R. Relationship between lower limb muscle strength and 6-minute walk test performance in stroke patients. J Rehabil Med. 2013;45(1):105-8.

99. Baetens T, De Kegel A, Calders P, Vanderstraeten G, Cambier D. Prediction of falling among stroke patients in rehabilitation. J Rehabil Med. 2011;43(10):876-83.

100. Suzuki M, Omori Y, Sugimura S, Miyamoto M, Sugimura Y, Kirimoto H, et al. Predicting recovery of bilateral upper extremity muscle strength after stroke. J Rehabil Med. 2011;43(10):935-43.

101. Kannus P. Isokinetic evaluation of muscular performance: implications for muscle testing and rehabilitation. Int J Sports Med. 1994;15 Suppl 1:S11-8.

102. Dietz V, Sinkjaer T. Spastic movement disorder: impaired reflex function and altered muscle mechanics. Lancet Neurol. 2007;6(8):725-33.

103. Priori A, Cogiamanian F, Mrakic-Sposta S. Pathophysiology of spasticity. Neurol Sci. 2006;27(4):s307-s9.

104. Vandenbroucke JP, Von Elm E, Altman DG, Gøtzsche PC, Mulrow CD, Pocock SJ, et al. Strengthening the Reporting of Observational Studies in Epidemiology (STROBE): explanation and elaboration. Annals of internal medicine. 2007;147(8):W-163-W-94.

105. Brunnstrom S. Motor testing procedures in hemiplegia: based on sequential recovery stages. Phys Ther. 1966;46(4):357.

106. Brott T, Adams H, Olinger CP, Marler JR, Barsan WG, Biller J, et al. Measurements of acute cerebral infarction: a clinical examination scale. Stroke. 1989;20(7):864-70.

107. Eng JJ, Chu KS, Dawson AS, Kim CM, Hepburn KE. Functional walk tests in individuals with stroke relation to perceived exertion and myocardial exertion. Stroke. 2002;33(3):756-61.

108. Flansbjer U-B, Holmbäck AM, Downham D, Lexell J. What change in isokinetic knee muscle strength can be detected in men and women with hemiparesis after stroke? Clin Rehabil. 2005;19(5):514-22.

109. BOHANNON RW, MORTON MG, WIKHOLM JB. Importance of four variables of walking to patients with stroke. Int J Rehabil Res. 1991;14(3):246-50.

110. Carod-Artal FJ, Coral LF, Trizotto DS, Moreira CM. The Stroke Impact Scale 3.0 Evaluation of Acceptability, Reliability, and Validity of the Brazilian Version. Stroke. 2008;39(9):2477-84.

111. Lin K-C, Fu T, Wu C-Y, Hsieh Y-W, Chen C-L, Lee P-C. Psychometric comparisons of the stroke impact scale 3.0 and stroke-specific quality of life scale. Qual Life Res. 2010;19(3):435-43.

112. Blum L, Korner-Bitensky N. Usefulness of the Berg Balance Scale in stroke rehabilitation: a systematic review. Phys Ther. 2008;88(5):559-66.

113. Hiengkaew V, Jitaree $\mathrm{K}$, Chaiyawat P. Minimal detectable changes of the Berg Balance Scale, Fugl-Meyer Assessment Scale, Timed "Up \& Go" Test, gait speeds, and 2minute walk test in individuals with chronic stroke with different degrees of ankle plantarflexor tone. Arch Phys Med Rehabil. 2012;93(7):1201-8.

114. Knutsson E, Mårtensson A, Gransberg L. Influences of muscle stretch reflexes on voluntary, velocity-controlled movements in spastic paraparesis. Brain. 1997;120(9):1621-33. 115. Symons TB, Vandervoort AA, Rice CL, Overend TJ, Marsh GD. Reliability of a single-session isokinetic and isometric strength measurement protocol in older men. The Journals of Gerontology Series A: Biological Sciences and Medical Sciences. 2005;60(1):114-9. 
116. Rhea MR. Determining the magnitude of treatment effects in strength training research through the use of the effect size. J Strength Cond Res. 2004;18(4):918-20.

117. Canning CG, Ada L, O'Dwyer N. Slowness to develop force contributes to weakness after stroke. Arch Phys Med Rehabil. 1999;80(1):66-70.

118. McCOMAS AJ. Human neuromuscular adaptations that accompany changes in activity. Med Sci Sports Exerc. 1994;26(12):1498-509.

119. Rosenfalck A, Andreassen S. Impaired regulation of force and firing pattern of single motor units in patients with spasticity. J Neurol Neurosurg Psychiatr. 1980;43(10):907-16.

120. Bandy WD, Timm KE. Relationship between peak torque, work, and power for knee flexion and extension in clients with grade i medial compartment sprains of the knee. J Orthop Sports Phys Ther. 1992;16(6):288-92.

121. Woodson C, Bandy WD, Curis D, Baldwin D. Relationship of isokinetic peak torque with work and power for ankle plantar flexion and dorsiflexion. J Orthop Sports Phys Ther. 1995;22(3):113-5. 


\section{ANEXOS}

\section{ANEXO I}

\section{Orpington Prognostic Scale}

DÉFICIT MOTOR DO BRAÇO: em decúbito dorsal, flexão de ombro a $90^{\circ}$, aplicar a resistência

Força Normal $(0,0)$

Contração frente à resistência $(0,4)$

Elevação contra a gravidade $(0,8)$

Contração não vence a gravidade. Contração Neuromuscular sem movimento $(1,2)$

Sem movimento $(1,6)$

PROPRIOCEPÇÃO (Olhos fechados): localizar polegar afetado

Corretamente $(0,0)$

Ligeira dificuldade $(0,4)$

Localiza seguimento do braço $(0,8)$

Incapaz $(1,2)$

\section{EQUILÍBRIO}

Anda 10 passos sem ajuda $(0,0)$

Mantém ortostatismo $(0,4)$

Mantém posição sentada $(0,8)$

Sem equilíbrio na posição sentada $(1,2)$

COGNIÇÃO (Teste Mental Hodkinson)

Pontuação $10(0,0)$

Pontuação 8-9 $(0,4)$

Pontuação 5-7 $(0,8)$

Pontuação 0-4 $(1,2)$

PONTUAÇÃO TOTAL: 1,6+motor+propriocepção+equilíbrio+cognição

\section{Classificação Prognóstica}

Bom prognóstico: $<3$ pontos

Moderado prognóstico: 3-5 pontos

Mal prognóstico: $>5$ pontos 


\section{Teste Mental Hodkinson (cada item vale 1 ponto)}

\begin{tabular}{|l|l|}
\hline Idade & \\
\hline Tempo (horário aproximado) & \\
\hline $\begin{array}{l}\text { Endereço para ser dito no fim do teste (pedir para paciente repetir para garantir que } \\
\text { ele tenha ouvido corretamente) }\end{array}$ & \\
\hline Ano & \\
\hline Nome do hospital & \\
\hline Reconhecer duas pessoas (ex: médico e a enfermeira) & \\
\hline Data de aniversário & \\
\hline Ano que começou a Primeira Guerra Mundial (ou algum evento famoso) & \\
\hline Nome do presidente & \\
\hline Contagem regressiva do 20 para o 1 & \\
\hline
\end{tabular}




\section{ANEXO II}

\section{Escala de Motricidade de Brunstrom}

Membros inferiores

1- nenhum movimento voluntário é realizado

2- sinergias associadas a movimentos fracos

3- tríplice flexão (flexão quadril, joelho, tornozelo)

4- com joelho fletido a $90^{\circ}$, paciente realiza dorsiflexão sem tirar o calcanhar do chão

5- flexão do joelho com quadril estendido / dorsiflexão com extensão do joelho / projeção do calcanhar

6 - em posição ortostática: abdução do quadril $\left(30^{\circ}\right)$;

em posição sentada: abdução e adução combinadas com inversão e eversão do tornozelo 


\section{ANEXO III}

\section{Escala Modificada de Ashworth}

\begin{tabular}{|c|c|l|}
\hline Grau & & Descrição \\
\hline & 0 & Sem aumento do tônus neuromuscular \\
\hline 1 & $\begin{array}{l}\text { Discreto aumento do tônus neuromuscular, manifestado pelo ato de prender e } \\
\text { soltar, ou por mínima resistência ao final da amplitude de movimento, } \\
\text { quando a parte (ou as partes) } \\
\text { afetada é movimentada em flexão e extensão. }\end{array}$ \\
\hline $1+$ & $\begin{array}{l}\text { Discreto aumento no tônus neuromuscular, manifestado pelo ato de prender, } \\
\text { seguido de mínima resistência através do resto (menos da metade) da } \\
\text { amplitude de movimento. }\end{array}$ \\
\hline 3 & $\begin{array}{l}\text { Marcante aumento do tônus neuromuscular através da maior parte da } \\
\text { amplitude de movimento, porém as partes afetadas são facilmente } \\
\text { movimentadas. }\end{array}$ \\
\hline & $\begin{array}{l}\text { Considerável aumento do tônus neuromuscular; movimentos passivos } \\
\text { dificultados. }\end{array}$ \\
\hline
\end{tabular}




\section{ANEXO IV}

\section{Stroke Impact Scale}

Essas questões são sobre problemas físicos que podem ter ocorrido como resultado do AVC.

\begin{tabular}{|l|c|c|c|c|c|}
\hline $\begin{array}{l}\text { 1. Na última semana como você } \\
\text { quantificaria a força... }\end{array}$ & $\begin{array}{c}\text { Força } \\
\text { normal }\end{array}$ & $\begin{array}{c}\text { Força } \\
\text { moderada }\end{array}$ & $\begin{array}{c}\text { Alguma } \\
\text { força }\end{array}$ & $\begin{array}{c}\text { Pouca } \\
\text { força }\end{array}$ & $\begin{array}{c}\text { Nenhuma } \\
\text { força }\end{array}$ \\
\hline $\begin{array}{l}\text { a. Do seu braço que foi mais afetado pelo } \\
\text { AVC? }\end{array}$ & 5 & 4 & 3 & 2 & 1 \\
\hline $\begin{array}{l}\text { b. Do seu aperto de mão no lado que foi } \\
\text { mais afetado pelo AVC? }\end{array}$ & 5 & 4 & 3 & 2 & 1 \\
\hline $\begin{array}{l}\text { c. Da sua perna que foi mais afetada pelo } \\
\text { AVC? }\end{array}$ & 5 & 4 & 3 & 2 & 1 \\
\hline $\begin{array}{l}\text { d. Do seu pé e tornozelo que foi mais } \\
\text { afetado pelo AVC? }\end{array}$ & 5 & 4 & 3 & 2 & 1 \\
\hline
\end{tabular}

Essas questões são sobre a sua memória e o seu pensamento.

\begin{tabular}{|l|c|c|c|c|c|}
\hline $\begin{array}{l}\text { 2. Na última semana, quanta } \\
\text { dificuldade você teve para... }\end{array}$ & $\begin{array}{c}\text { Nenhuma } \\
\text { dificuldade }\end{array}$ & $\begin{array}{c}\text { Dificuldade } \\
\text { leve }\end{array}$ & $\begin{array}{c}\text { Dificuldade } \\
\text { moderada }\end{array}$ & $\begin{array}{c}\text { Muita } \\
\text { dificuldade }\end{array}$ & $\begin{array}{c}\text { Extrema } \\
\text { dificuldade }\end{array}$ \\
\hline $\begin{array}{l}\text { a. Lembrar-se de coisas que as } \\
\text { pessoas acabaram de lhe falar? }\end{array}$ & 5 & 4 & 3 & 2 & 1 \\
\hline $\begin{array}{l}\text { b. Lembrar-se de coisas que } \\
\text { aconteceram no dia anterior? }\end{array}$ & 5 & 4 & 3 & 2 & 1 \\
\hline $\begin{array}{l}\text { c. Lembrar-se de fazer coisas (manter } \\
\text { compromissos marcados, tomar a } \\
\text { medicação)? }\end{array}$ & 5 & 4 & 3 & 2 & 1 \\
\hline $\begin{array}{l}\text { d. Lembrar o dia da semana? } \\
\text { e. Concentrar-se? }\end{array}$ & 5 & 4 & 3 & 2 & 1 \\
\hline f. Raciocinar rapidamente? & 5 & 4 & 3 & 2 & 1 \\
\hline g. Resolver problemas do dia-a-dia? & 5 & 4 & 3 & 2 & 1 \\
\hline
\end{tabular}


Essas questões são sobre seus sentimentos, mudanças de humor e capacidade para controlar suas emoções desde o AVC.

\begin{tabular}{|l|c|c|c|c|c|}
\hline $\begin{array}{l}\text { 3. Na última semana, com que } \\
\text { frequência você... }\end{array}$ & Nunca & $\begin{array}{c}\text { Raras } \\
\text { vezes }\end{array}$ & $\begin{array}{c}\text { Algumas } \\
\text { vezes }\end{array}$ & $\begin{array}{c}\text { A maioria } \\
\text { das vezes }\end{array}$ & $\begin{array}{c}\text { O tempo } \\
\text { todo }\end{array}$ \\
\hline a. Sentiu-se triste? & 5 & 4 & 3 & 2 & 1 \\
\hline b. Sentiu-se sozinho? & 5 & 4 & 3 & 2 & 1 \\
\hline $\begin{array}{l}\text { c. Sentiu que é uma carga para os } \\
\text { outros? }\end{array}$ & 5 & 4 & 3 & 2 & 1 \\
\hline d. Sentiu-se desesperançoso? & 5 & 4 & 3 & 2 & 1 \\
\hline e. Culpou-se por erros que cometeu? & 5 & 4 & 3 & 2 & 1 \\
\hline f. Divertiu-se como antes? & 5 & 4 & 3 & 2 & 1 \\
\hline g. Sentiu-se muito nervoso (a)? & 5 & 4 & 3 & 2 & 1 \\
\hline h. Sentiu que a vida vale a pena? & 5 & 4 & 3 & 2 & 1 \\
\hline i. Sorriu ao menos uma vez ao dia? & 5 & 4 & 3 & 2 & 1 \\
\hline
\end{tabular}

As questões a seguir são relativas à sua capacidade para comunicar-se com outras pessoas, assim como compreender o que você lê ou ouve numa conversa.

\begin{tabular}{|l|c|c|c|c|c|}
\hline $\begin{array}{l}\text { 4. Na última semana, quanta } \\
\text { dificuldade você teve para... }\end{array}$ & $\begin{array}{c}\text { Nenhuma } \\
\text { dificuldade }\end{array}$ & $\begin{array}{c}\text { Leve } \\
\text { dificuldade }\end{array}$ & $\begin{array}{c}\text { Moderada } \\
\text { dificuldade }\end{array}$ & $\begin{array}{c}\text { Muita } \\
\text { dificuldad } \\
\text { e }\end{array}$ & $\begin{array}{c}\text { Extrema } \\
\text { dificuldade }\end{array}$ \\
\hline $\begin{array}{l}\text { a. Dizer o nome de alguém que estava } \\
\text { na sua frente? }\end{array}$ & 5 & 4 & 3 & 2 & 1 \\
\hline $\begin{array}{l}\text { b. Entender o que estava sendo dito } \\
\text { em uma conversa? }\end{array}$ & 5 & 4 & 3 & 2 & 1 \\
\hline $\begin{array}{l}\text { c. Responder a perguntas? } \\
\text { d. Nomear objetos corretamente? }\end{array}$ & 5 & 4 & 3 & 2 & 1 \\
\hline $\begin{array}{l}\text { e. Participar de uma conversa em } \\
\text { grupo? }\end{array}$ & 5 & 4 & 3 & 3 & 2 \\
\hline f. Falar ao telefone? & 5 & 4 & 3 & 2 & 1 \\
\hline $\begin{array}{l}\text { g. Ligar para alguém, selecionando o } \\
\text { número e discando? }\end{array}$ & 5 & 4 & 3 & 2 & 1 \\
\hline
\end{tabular}


As questões a seguir são sobre atividades que você habitualmente realizaria durante um dia comum.

\begin{tabular}{|c|c|c|c|c|c|}
\hline $\begin{array}{l}\text { 5. Nas últimas duas semanas, quanta } \\
\text { dificuldade você teve para... }\end{array}$ & $\begin{array}{l}\text { Nenhuma } \\
\text { dificuldade }\end{array}$ & $\begin{array}{c}\text { Pouca } \\
\text { dificuldade }\end{array}$ & $\begin{array}{l}\text { Moderada } \\
\text { dificuldade }\end{array}$ & $\begin{array}{c}\text { Muita } \\
\text { dificuldade }\end{array}$ & $\begin{array}{l}\text { Não } \\
\text { consegui } \\
\text { realizar }\end{array}$ \\
\hline a. Cortar a comida com garfo e faca? & 5 & 4 & 3 & 2 & 1 \\
\hline b. Vestir a parte de cima do seu corpo? & 5 & 4 & 3 & 2 & 1 \\
\hline c. Tomar banho sozinho? & 5 & 4 & 3 & 2 & 1 \\
\hline d. Cortar as unhas dos pés? & 5 & 4 & 3 & 2 & 1 \\
\hline e. Chegar ao banheiro a tempo? & 5 & 4 & 3 & 2 & 1 \\
\hline $\begin{array}{l}\text { f. Controlar sua bexiga (não perder } \\
\text { urina)? }\end{array}$ & 5 & 4 & 3 & 2 & 1 \\
\hline $\begin{array}{l}\text { g. Controlar seu intestino (não perder } \\
\text { fezes)? }\end{array}$ & 5 & 4 & 3 & 2 & 1 \\
\hline $\begin{array}{l}\text { h. Realizar serviços domésticos leves } \\
\text { (limpar poeira, arrumar a cama, tirar o } \\
\text { lixo, lavar louça)? }\end{array}$ & 5 & 4 & 3 & 2 & 1 \\
\hline i. Fazer compras? & 5 & 4 & 3 & 2 & 1 \\
\hline $\begin{array}{l}\text { j. Realizar serviços domésticos pesados } \\
\text { (passar aspirador, lavar roupa, } \\
\text { jardinagem)? }\end{array}$ & 5 & 4 & 3 & 2 & 1 \\
\hline
\end{tabular}

As questões seguintes são sobre sua capacidade de se deslocar em casa e na comunidade.

\begin{tabular}{|c|c|c|c|c|c|}
\hline $\begin{array}{c}\text { 6. Nas últimas duas } \\
\text { semanas, quanta } \\
\text { dificuldade você teve } \\
\text { para... }\end{array}$ & $\begin{array}{c}\text { Nenhuma } \\
\text { dificuldade }\end{array}$ & $\begin{array}{c}\text { Leve } \\
\text { dificuldade }\end{array}$ & $\begin{array}{c}\text { Moderada } \\
\text { dificuldade }\end{array}$ & $\begin{array}{c}\text { Muita } \\
\text { dificuldade }\end{array}$ & $\begin{array}{c}\text { Não } \\
\text { consegui } \\
\text { realizar }\end{array}$ \\
\hline $\begin{array}{c}\text { a. Ficar sentado sem } \\
\text { perder o equilíbrio? }\end{array}$ & 5 & 4 & 3 & 2 & 1 \\
\hline $\begin{array}{c}\text { b. Ficar em pé sem perder } \\
\text { o equilíbrio? }\end{array}$ & 5 & 4 & 3 & 2 & 1 \\
\hline $\begin{array}{c}\text { c. Caminhar sem perder o } \\
\text { equilíbrio? }\end{array}$ & 5 & 4 & 3 & 2 & 1 \\
\hline $\begin{array}{c}\text { d. Se deslocar da cama } \\
\text { para a cadeira? }\end{array}$ & 5 & 4 & 3 & 2 & 1 \\
\hline e. Andar um quarteirão? & 5 & 4 & 3 & 2 & 1 \\
\hline $\begin{array}{c}\text { f. Andar rápido? } \\
\text { g. Subir um lance de } \\
\text { escadas? }\end{array}$ & 5 & 4 & 3 & 2 & 1 \\
\hline h. Subir vários lances de \\
escada?
\end{tabular}


As questões a seguir são sobre a sua capacidade de usar a mão mais afetada pelo AVC.

\begin{tabular}{|l|c|c|c|c|c|}
\hline $\begin{array}{l}\text { 7. Nas últimas duas semanas, } \\
\text { quanta dificuldade você teve em } \\
\text { usar a mão que foi mais afetada } \\
\text { pelo AVC para... }\end{array}$ & $\begin{array}{c}\text { Nenhuma } \\
\text { dificuldade }\end{array}$ & $\begin{array}{c}\text { Leve } \\
\text { dificuldade }\end{array}$ & $\begin{array}{c}\text { Moderada } \\
\text { dificuldade }\end{array}$ & $\begin{array}{c}\text { Muita } \\
\text { dificuldade }\end{array}$ & $\begin{array}{c}\text { Não } \\
\text { consegui } \\
\text { realizar }\end{array}$ \\
\hline $\begin{array}{l}\text { a. Carregar objetos pesados } \\
\text { (sacola de compras)? }\end{array}$ & 5 & 4 & 3 & 2 & 1 \\
\hline b. Girar a maçaneta da porta? & 5 & 4 & 3 & 2 & 1 \\
\hline c. Abrir uma lata ou jarra? & 5 & 4 & 3 & 2 & 1 \\
\hline d. Amarrar o cadarço do sapato? & 5 & 4 & 3 & 2 & 1 \\
\hline e. Pegar uma moeda? & 5 & 4 & 3 & 2 & 1 \\
\hline
\end{tabular}

As questões a seguir são como o AVC tem afetado a sua capacidade em participar de atividades anteriormente habituais, coisas significativas para você, e que o ajudam a encontrar sentido para a vida.

\begin{tabular}{|l|c|c|c|c|c|}
\hline $\begin{array}{l}\text { 8. Nas últimas quatro semanas, quanto } \\
\text { tempo você esteve limitado em... }\end{array}$ & Nunca & $\begin{array}{c}\text { Pouco } \\
\text { tempo }\end{array}$ & $\begin{array}{c}\text { Grande } \\
\text { parte do } \\
\text { tempo }\end{array}$ & $\begin{array}{c}\text { A maior } \\
\text { parte do } \\
\text { tempo }\end{array}$ & $\begin{array}{c}\text { O tempo } \\
\text { todo }\end{array}$ \\
\hline $\begin{array}{l}\text { a. Seu trabalho (assalariado, voluntário, } \\
\text { outros)? }\end{array}$ & 5 & 4 & 3 & 2 & 1 \\
\hline $\begin{array}{l}\text { b. Suas atividades sociais? } \\
\text { c. Atividades recreativas tranquilas (artes, } \\
\text { leitura)? }\end{array}$ & 5 & 4 & 3 & 2 & 1 \\
\hline $\begin{array}{l}\text { d. Atividades recreativas ativas (esporte, } \\
\text { passeios, viagens)? }\end{array}$ & 5 & 4 & 3 & 2 & 1 \\
\hline $\begin{array}{l}\text { e. Seu papel como membro da família } \\
\text { elou amigo? }\end{array}$ & 5 & 4 & 3 & 2 & 1 \\
\hline $\begin{array}{l}\text { f. Sua participação em atividades } \\
\text { espirituais, religiosas? }\end{array}$ & 5 & 4 & 3 & 2 & 1 \\
\hline $\begin{array}{l}\text { g. Sua capacidade de controlar a vida } \\
\text { como você deseja? }\end{array}$ & 5 & 4 & 3 & 2 & 1 \\
\hline \begin{tabular}{l} 
i. Sua capacidade de ajudar os outros? \\
\hline
\end{tabular} & 5 & 4 & 3 & 2 & 1 \\
\hline
\end{tabular}




\section{Recuperação do AVC}

Em uma escala de 0 a 100, com 100 representando recuperação completa e 0 representando nenhuma recuperação, quanto você acha que se recuperou do AVC?

100 Recuperação completa

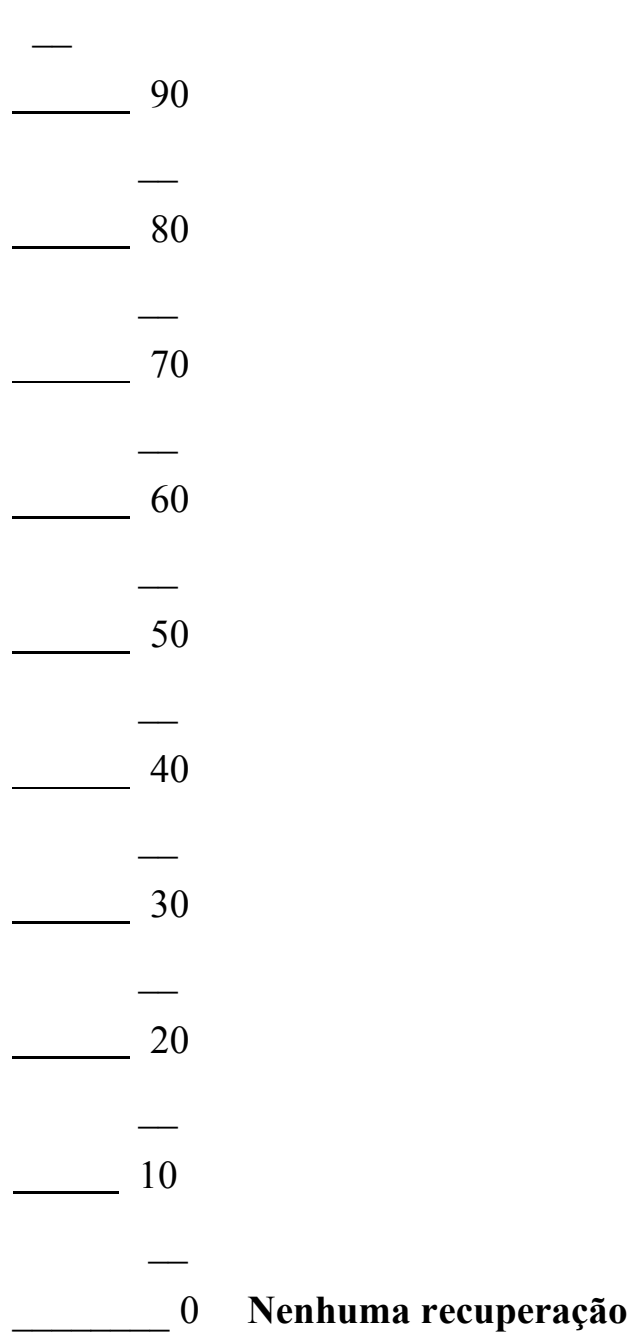




\section{ANEXO V}

\section{Escala de Equilíbrio de Berg}

1. Posição sentada para posição em pé

Instruções: Por favor, levante-se. Tente não usar as suas mãos como suporte

( 4 ) capaz de se levantar sem utilizar as mãos e estabilizar-se de forma independente

( 3 ) capaz de se levantar de forma independente utilizando as mãos

( 2 ) capaz de se levantar utilizando as mãos após diversas tentativas

( 1 ) necessita de ajuda mínima para se levantar ou estabilizar

( 0 ) necessita de ajuda moderada ou máxima para se levantar

2. Permanecer em pé sem apoio

Instruções: Por favor, fique em pé, durante 2 minutos sem se apoiar.

( 4 ) capaz de permanecer em pé com segurança por 2 minutos

( 3 ) capaz de permanecer em pé por 2 minutos com supervisão

( 2 ) capaz de permanecer em pé por 30 segundos sem apoio

( 1 ) necessita de várias tentativas para permanecer em pé por 30 segundos sem apoio

( 0 ) incapaz de permanecer em pé por 30 segundos sem apoio

Se for capaz de permanecer em pé por 2 minutos sem apoio, registe o número total de pontos no item número 3 e continue com o item número 4 .

3. Permanecer sentado sem apoio nas costas, mas com os pés apoiados no chão ou num banquinho

Instruções: Por favor, fique sentado sem apoiar as costas com os braços cruzados por 2 minutos.

( 4 ) capaz de permanecer sentado com segurança e com firmeza por 2 minutos

( 3 ) capaz de permanecer sentado por 2 minutos sob supervisão

( 2 ) capaz de permanecer sentado por 30 segundos

( 1 ) capaz de permanecer sentado por 10 segundos

( 0 ) incapaz de permanecer sentado sem apoio durante 10 segundos

4. Posição em pé para posição sentada

Instruções: Por favor, sente-se.

( 4 ) senta-se com segurança com uso mínimo das mãos

( 3 ) controla a descida utilizando as mãos

( 2 ) utiliza a parte posterior das pernas contra a cadeira para controlar a descida

( 1 ) senta-se de forma independente, mas tem descida sem controle

( 0 ) necessita de ajuda para sentar-se 


\section{Transferências}

Instruções: Arrume as cadeiras perpendicularmente ou uma de frente para a outra para uma transferência em pivô.

Por favor, transferir-se de uma cadeira com apoio de braço para uma cadeira sem apoio de braço, e vice-versa

( 4 ) capaz de se transferir com segurança com uso mínimo das mãos

( 3 ) capaz de se transferir com segurança com o uso das mãos

( 2 ) capaz de se transferir seguindo orientações verbais com/ou supervisão

( 1 ) necessita de uma pessoa para ajudar

( 0 ) necessita de duas pessoas para ajudar ou supervisionar para realizar a tarefa com segurança

6. Permanecer em pé sem apoio com os olhos fechados

Instruções: Por favor, fique em pé e feche os olhos por 10 segundos.

( 4 ) capaz de permanecer em pé por 10 segundos com segurança

( 3 ) capaz de permanecer em pé por 10 segundos com supervisão

( 2 ) capaz de permanecer em pé por 3 segundos

( 1 ) incapaz de permanecer com os olhos fechados durante 3 segundos, mas mantém-se em pé

( 0 ) necessita de ajuda para não cair

7. Permanecer em pé sem apoio com os pés juntos

Instruções: Por favor, junte os seus pés e fique em pé sem se apoiar.

( 4 ) capaz de posicionar os pés juntos de forma independente e permanecer por 1 minuto com segurança

( 3 ) capaz de posicionar os pés juntos de forma independente e permanecer por 1 minuto com supervisão

( 2 ) capaz de posicionar os pés juntos de forma independente e permanecer por 30 segundos (

1 ) necessita de ajuda para se posicionar, mas é capaz de permanecer com os pés juntos durante 15 segundos

( 0 ) necessita de ajuda para se posicionar e é incapaz de permanecer nessa posição por 15 segundos

8. Alcançar à frente com o braço entendido permanecendo em pé

Instruções: Levante o braço a $90^{\circ}$. Estique os dedos e tente alcançar a frente o mais longe possível.

(O examinador posiciona a régua no fim da ponta dos dedos A medida registada é a distância que os dedos conseguem alcançar na inclinação).

Por Favor, se possível, use ambos os braços de forma a evitar rotação do tronco.

( 4 ) pode avançar à frente mais que $25 \mathrm{~cm}$ com segurança

( 3 ) pode avançar à frente mais que $12,5 \mathrm{~cm}$ com segurança

( 2 ) pode avançar à frente mais que $5 \mathrm{~cm}$ com segurança

( 1 ) pode avançar à frente, mas necessita de supervisão

( 0 ) perde o equilíbrio na tentativa, ou necessita de apoio externo 
9. Pegar um objeto do chão a partir de uma posição em pé.

Instruções: Por favor, pegue o objeto que está na frente dos seus pés.

( 4 ) capaz de pegar o sapato/chinelo com facilidade e segurança

( 3 ) capaz de pegar o sapato/chinelo, mas necessita de supervisão

( 2 ) incapaz de pegá-lo, mas se estica até ficar a $2-5 \mathrm{~cm}$ do chinelo e mantém o equilíbrio de forma independente

( 1 ) incapaz de pegá-lo, necessitando de supervisão enquanto está tentando

( 0 ) incapaz de fazer, ou necessita de ajuda para não perder o equilíbrio ou cair

10. Virar-se e olhar para trás por cima dos ombros direito e esquerdo enquanto permanece em pé.

Instruções: Por favor, vire-se para olhar diretamente atrás de você por cima, do seu ombro esquerdo sem tirar os pés do chão. Faça o mesmo por cima do ombro direito.

( 4 ) olha para trás de ambos os lados com uma boa distribuição do peso

( 3 ) olha para trás somente de um lado; o lado contrário demonstra menor distribuição do peso

( 2 ) vira somente para os lados, mas mantém o equilíbrio

( 1 ) necessita de supervisão para virar

( 0 ) necessita de ajuda para não perder o equilíbrio ou cair

11. Girar 360 graus

Instruções: Por favor, gire sobre si mesmo. Faça uma pausa. Gire em sentido contrário.

( 4 ) capaz de girar 360 graus com segurança em 4 segundos ou menos

( 3 ) capaz de girar 360 graus com segurança somente para um lado em 4 segundos ou menos

( 2 ) capaz de girar 360 graus com segurança, mas lentamente

( 1 ) necessita de supervisão próxima ou orientações verbais

( 0 ) necessita de ajuda enquanto gira

12. Posicionar os pés alternadamente no degrau/banquinho enquanto permanece em pé sem apoio

Instruções: Por favor, toque cada pé alternadamente no degrau/banquinho. Continue até que cada pé tenha tocado o degrau/banquinho quatro vezes.

( 4 ) capaz de permanecer em pé de forma independente e com segurança, completando 8 movimentos em 20 segundos

( 3 ) capaz de permanecer em pé de forma independente e completar 8 movimentos em mais que 20 segundos

( 2 ) capaz de completar 4 movimentos sem ajuda

( 1 ) capaz de completar mais que 2 movimentos com o mínimo de ajuda

( 0 ) incapaz de fazer, ou necessita de ajuda para não cair 
13. Permanecer em pé sem apoio com um pé à frente Instruções: Coloque um pé diretamente à frente do outro na mesma linha. Se achar, que não irá conseguir, coloque o pé um pouco mais à frente do outro e levemente para o lado.

( 4 ) capaz de colocar um pé imediatamente à frente do outro de forma independente, e permanecer por 30 segundos

( 3 ) capaz de colocar um pé um pouco mais à frente do outro e levemente para o lado de forma independente, e permanecer por 30 segundos

( 2 ) capaz de dar um pequeno passo de forma independente e permanecer por 30 segundos

( 1 ) necessita de ajuda para dar o passo, porém permanece por 15 segundos

( 0 ) perde o equilíbrio ao tentar dar um passo ou ficar de pé

14. Permanecer em pé sobre uma perna

Instruções: Fique em pé sobre uma perna o máximo que puder sem se segurar.

( 4 ) capaz de levantar uma perna de forma independente e permanecer por mais que 10 segundos

( 3 ) capaz de levantar uma perna de forma independente e permanecer por 5-10 segundos

( 2 ) capaz de levantar uma perna de forma independente e permanecer por 3-4 segundos

( 1 ) tenta levantar uma perna, mas é incapaz de permanecer por 3 segundos, embora permaneça em pé de forma independente

( 0 ) incapaz de fazer, ou necessita de ajuda para não cair

Resultado Total (Máximo $=56$ ):

Entre 41 e 56 pontos - baixo risco de queda

Entre 21 e 40 pontos - médio risco de queda

Entre 0 e 20 pontos - elevado risco de queda 


\section{ANEXO VI}

\section{TERMO DE CONSENTIMENTO LIVRE E ESCLARECIDO}

N. ${ }^{\circ}$ Registro CEP: 36769514.0.0000.0022

Título do Projeto: DIFERENTES AVALIAÇÕES DA FORÇA NEUROMUSCULAR E SUAS RELAÇÕES COM VARIÁVEIS CLÍNICAS DO ACIDENTE VASCULAR ENCEFÁLICO: ANÁLISE DISCRIMINANTE E REGRESSÃO.

Prezado Sr (a),

Você está sendo convidado (a) a participar de uma pesquisa que estudará as avaliações da força neuromuscular dos músculos extensores de joelho das duas pernas e relacionar com avaliações clínicas de marcha, equilíbrio e impacto do Acidente Vascular Encefálico (AVC).

Você foi selecionado (a) porque não apresenta nenhuma condição clínica que impossibilite a realização dos protocolos (teste de força e caminhada), consegue caminhar 10 metros sem assistência e compreende pelo menos um comando verbal e está sendo acompanhado na Rede SARAH de Hospitais de Reabilitação.

Você participará de uma entrevista na qual será instruído verbalmente sobre os procedimentos do estudo e convidado a participar. Em seguida, ocorrerá uma avaliação através de questionário e exame físico na qual será verificada o grau de severidade do AVC, motricidade e a espasticidade, além de uma balança e estadiômetro para medir a massa corporal e a estatura, respectivamente. Serão avaliados também a marcha, através de uma caminhada de 6 minutos e outra de 14 metros; o equilíbrio através de uma escala com exame físico; e o impacto do AVC através de um questionário. Como o projeto pretende correlacionar essas medidas com a força neuromuscular dos membros inferiores, serão realizadas avaliações da força em um dinamômetro isocinético. Após a calibragem dos equipamentos, o(a) senhor(a) deverá realizar os movimentos requeridos pelo protocolo de exercício do joelho, sendo que os resultados poderão ser visualizados em uma tela de computador à sua frente. Sempre que tiver dúvidas, nós o instruiremos. Ressalta-se que todos os equipamentos de medida utilizados são protegidos contra descarga elétrica, não havcndo riscos desta natureza. Solicito permissão para obtenção de dados sócio demográficos de seu prontuário, os quais serão mantidos sob sigilo e sua identidade será preservada.

Não há riscos diretos relacionados ao procedimento que será realizado neste estudo, no entanto, de acordo com a Resolução 466/12, zelando por evitar ou minimizar qualquer situação de desconforto ou constrangimento para falar sobre qualquer parte do tema proposto, 
será garantida a interrupção imediata da entrevista. Será garantida a manutenção do sigilo e da privacidade dos participantes em todas as fases da pesquisa, assim como a indenização diante de eventuais danos decorrentes da pesquisa.

Sua participação é muito importante e voluntária. Você não terá nenhum gasto e também não receberá nenhum pagamento por participar desse estudo.

As informações obtidas nesse estudo serão confidenciais, sendo assegurado o sigilo sobre sua participação, quando da apresentação dos resultados em publicação científica ou educativa, uma vez que os resultados serão sempre apresentados como retrato de um grupo e não de uma pessoa. Você poderá se recusar a participar ou a responder algumas das questões a qualquer momento, não havcndo nenhum prejuízo pessoal se esta for a sua decisão.

Os resultados dessa pesquisa servirão para a compreensão quanto a sua condição de equilíbrio, da força neuromuscular dos membros inferiores e do impacto do AVC. Além disso, os possíveis achados poderão embasar cientificamente novas formas de avaliação de força neuromuscular dos membros inferiores em indivíduos acometidos pelo AVC.

Você receberá uma cópia deste termo onde consta o telefone e o endereço do pesquisador responsável e do Comitê de Ética em Pesquisa, podendo tirar suas dúvidas sobre o projeto e sua participação, agora ou a qualquer momento.

Pesquisador responsável: Rodrigo Rodrigues Gomes Costa

Endereço: SHIN QL 13 Área Especial C, Lago Norte/ Brasília - DF, 71535-005

Telefones: (61) 3319-1908/8160-6567

Este estudo foi aprovado pelo Comitê de Ética em Pesquisa da Associação das Pioneiras Sociais, telefone: (61) 3319-1494, email: comiteeticapesquisa@,sarah.br ou endereço: SMHS 501 BLOCO A, $4^{\circ}$ andar.

Dou meu consentimento de livre e espontânea vontade para participar deste estudo.

Nome do participante

Assinatura do participante ou representante legal

Data

Obrigada por sua colaboração.

Nome e Assinatura da pesquisador

Data 